\title{
Expecting the Unexpected: Emissions Uncertainty and Environmental Market Design Online Appendix
}

\author{
Severin Borenstein, James Bushnell, \\ Frank A. Wolak, and Matthew Zaragoza-Watkins
}

August 24, 2019

This appendix presents detailed descriptions of the modeling methods, assumptions, and additional results from the paper "Expecting the Unexpected: Emissions Uncertainty and Environmental Market Design." The Appendix is organized into three major sections. Section A.1 provides a description of the primary method and data we use to estimate the distribution of future business-as-usual (BAU) greenhouse gas (GHG) emissions, as well as three alternative approaches varying in sophistication and parsimony. Section A.2 details how we construct price non-responsive abatement, price-responsive abatement, and the aggregate equilibrium price in the cap-and-trade market. Section A.3 presents additional estimates derived using alternative assumptions and modeling approaches outlined in the main text.

\section{A.1 Modeling Business as Usual GHG Emissions}

This section presents the details of our cointegrated vector autoregression (VAR) modeling framework and the methodology we employ to estimate the joint distribution of annual BAU GHG emissions from 2013 to 2020. There are three sources of uncertainty associated with modeling BAU emissions over 2013 to 2020. The first source is uncertainty over the correct parametric form of the true data generation process. The second source is uncertainty over the value of the vector of parameters of the true data generation process. The third source is uncertainty over the future values of unobservable (to the econometrician) factors driving the data generation process. Our modeling framework accounts for the second and third sources of uncertainty, and our sensitivity analysis assesses the impact of the first source of uncertainty.

The remainder of this section presents the details of our co-integrated vector autoregression (VAR) modeling framework and the methodology we employ to estimate the joint distribution of annual BAU GHG emissions from 2013 to 2020 . To assess the sensitivity of our estimate of the joint distribution of future BAU emissions to our parametric econometric model choice, we also present estimation and simulation results for three alternative statistical models for BAU emissions. There is significant agreement between the mean forecast of annual broad scope GHG emissions and mean forecast of cumulative covered GHG emissions for the period 2013 to 2020 from these models. The models produce somewhat different confidence intervals for GHG emissions over the 2013 to 2020 period, but they all support our conclusion that BAU GHG emissions uncertainty creates a low probability of an interior allowance price equilibrium in the cap-and-trade program. 


\section{A.1.1 Overview of Estimation}

Several features of our co-integrated VAR are chosen to match the time series relationships between the seven variables implied by economic theory and existing state policies to determine BAU GHG emissions. We allow for the fact that all seven variables exhibit net positive or negative growth over our sample period and model them as stochastic processes that are second-order stationary in growth rates rather than secondorder stationary in levels. The results of unit root tests reported below for each of the individual time series are consistent with this modeling assumption. We also impose restrictions on the parameters of the VAR implied by cointegrating relationships between these seven variables that are supported by the results of cointegration tests reported below. Engle and Yoo (1987) show that imposing the parameter restrictions implied by cointegrating relationships between variables in a VAR improves the forecasting accuracy of the estimated model. We have confirmed this result by comparing the size of the confidence intervals for BAU emssions from our VAR model with and without the restrictions on the parameters of the VAR implied by these cointegrating relationships imposed. The confidence intervals without the cointegration restrictions imposed are uniformly larger for all years from 2013 to 2020.

The cointegrated VAR relies on seven annual magnitudes for the sample period 1990 to 2010. Let $X_{t}=\left(X_{1 t}, X_{2 t}, \ldots, X_{7 t}\right)^{\prime}$ denote the vector composed of the following annual variables:

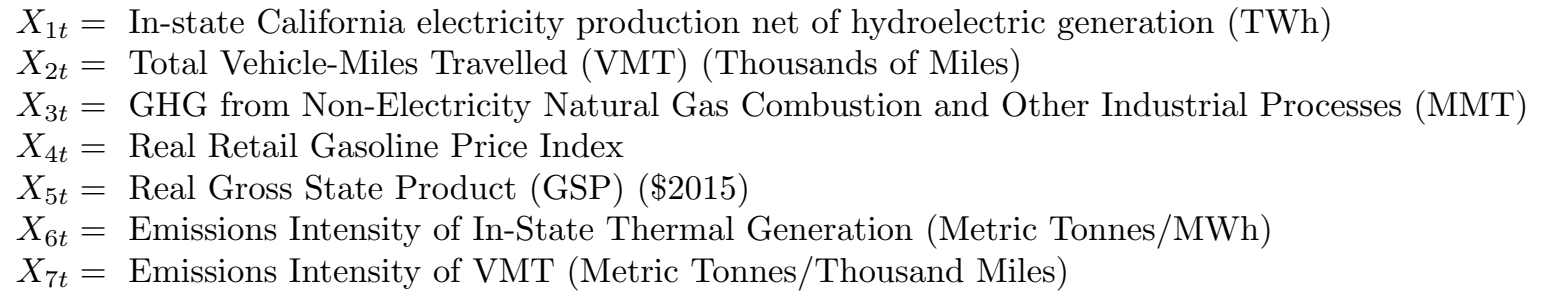

where the definitions of the units abbreviations are: $\mathrm{TWh}=$ terawatt-hours, $\mathrm{MMT}=$ millions of metric tonnes, $\mathrm{VMT}=$ vehicle miles traveled, $\mathrm{MWh}=$ megawatt-hours. All dollar magnitudes are expressed in 2015 real dollars, converted using the annual California Consumer Price Index (CPI-U). All GHG emissions are in metric tonnes of $\mathrm{CO}_{2}$-equivalents. We include real Gross State Product (GSP) to capture the empirical regularity observed both over time and across jurisdictions that a higher level of economic activity leads to greater energy consumption and GHG emissions. The price of gasoline reflects the fact that changes in transport fuel prices change the energy intensity of economic activity and total vehicle miles traveled.

We estimate the VAR in terms of the logarithms of the elements $X_{t}=\left(X_{1 t}, X_{2 t}, \ldots, X_{7 t}\right)$. We then use a bootstrap-based re-sampling scheme to compute an estimate of the distribution of $X_{t}$ from 2013 to 2020 that accounts for both estimation error in the parameters of the VAR and uncertainty in the future realizations of the stochastic process driving the VAR. A number of transformations of several elements of $X_{t}$ are required to simulate the distribution of GHG emissions for 2013 to 2020 . In the next subsection, we discuss estimation of the VAR and how it is used to simulate future values of the elements of $X_{t}$. In the following subsection, we explain the transformations of the simulated value of $X_{t}$ used to derive estimates of the distribution of BAU GHG emissions from 2013 to 2020.

\section{A.1.2 Data Sources and Construction}

To compute the GHG emissions intensities of the in-state electricity production and the transportation sector from 1990 to 2010 that enter the VAR model, we require data on the annual emissions from in-state electricity production and annual emissions from the transportation sector to enter the numerator of each of these intensities. Annual emissions from the large industrial processes and the residential and commercial natural gas sector from 1990 to 2010 is the final GHG emissions-related time series required to estimate the 
VAR. ${ }^{1}$ To construct these data, we start with data on annual emissions for each covered sector in California for 1990 to 2010.

Annual emissions levels for each covered sector are taken from the 1990-2004 Greenhouse Gas Emissions Inventory and the 2000-2014 Greenhouse Gas Emissions Inventory (hereafter, Inventory). ${ }^{2}$ This is the longest series of consistently measured emissions data and the basis for developing the 1990 statewide emissions level and 2020 emissions limit required by AB 32. The annual Inventory dataset was prepared by California Air Resources Board (ARB) staff and relies primarily on state, regional or national data sources, rather than individual facility-specific emissions. The Inventory's top-down approach to quantifying emissions differs importantly from the bottom-up method of accounting for facility-specific emissions under the cap-andtrade program. In particular, the Inventory likely overstates emissions from industrial activity relative to those covered in the first compliance period of the cap-and-trade program.

We investigate the impact of this difference by comparing the Inventory data to annual data collected under the Mandatory Reporting Regulation (MRR), which is the methodology used to calculate an entity's compliance obligation under the cap-and-trade program. ${ }^{3}$. From 2013 onward the MRR dataset was used to officially assign emissions obligations to covered entities and is therefore the highest quality measure of emissions under the cap-and-trade program. Prior to 2013 the MRR data were non-binding and used to give covered entities experience with the reporting interface. We therefore do not rely upon data prior to 2013. For the covered years 2013 and 2014 we aggregate emissions across four source categories (domestic electricity, imported electricity, transportation, and natural gas/industrial) and compare the 2 year average for these sectors to the same aggregated averages from the emissions inventory data. This comparison is used to generate an adjustment factor that calibrates the emissions inventory data so that it aligns perfectly with the MRR data in 2013-2014 and applies this adjustment to all prior years of the emissions inventory data.

One remaining adjustment necessary for the first compliance period was isolating the component of natural gas emissions that were produced by large industrial sources that were directly covered under the program from its start in 2013. Comparing the MRR and Inventory industrial emissions data series shows annual Inventory industrial emissions to be fifteen percent higher than MRR industrial emissions, on average. We address this difference by forecasting industrial capped source emissions in the first compliance period using the Inventory industrial emissions data series adjusted downward by fifteen percent. The remaining 15 percent of industrial emissions are assigned to the natural gas/other category.

The remaining data that enter the VAR come from a variety of California state and federal sources:

California GSP is collected from the Bureau of Economic Analysis (BEA). ${ }^{4}$ Gasoline prices are a price index for the San Francisco Bay Area from the Bureau of Labor Statistics. ${ }^{5}$ In-state electric generation is collected from the California Energy Commission (CEC). ${ }^{6}$ All dollar figures are adjusted to constant 2015 dollars using the California consumer price index. ${ }^{7}$

Additionally, we adjust transportation sector emissions to account for differences between how emissions and driving activity are measured. Our primary measure of VMT is compiled from a series of state-level transportation surveys administered by the National Highway Transportation Safety Administration's (NHTSA) Office of Highway Information (OHI). These data capture on-road VMT and were independently constructed

\footnotetext{
${ }^{1}$ Emissions from the off-road consumption of diesel also comprises a small component of the "other" category.

${ }^{2}$ The Inventory is available at: http://www.arb.ca.gov/cc/inventory/inventory.htm.

${ }^{3}$ Information on the MRR is available at: http://www.arb.ca.gov/cc/reporting/ghg-rep/reported-data/ghg-reports.htm.

${ }^{4}$ Gross Domestic Product by State is available at: http://www.bea.gov/regional/index.htm\#data.

${ }^{5}$ See https://alfred.stlouisfed.org/series?seid=CUURA422SS47014. We use these data rather than price data from the Energy Information Administration by state, because the EIA data do not go back to the 1970s, as we need for the two-sample error correction model described below. We adjust this nominal price index for inflation.

${ }^{6}$ In-state California electric generation and consumption are available from the CEC at http://energyalmanac.ca.gov/electricity/index.html.

${ }^{7}$ Available at http://www.dof.ca.gov/Forecasting/Economics/Indicators/Inflation/documents/BBCYCPI0519.xlsx.
} 
Table A.1: VAR Estimation Dataset

\begin{tabular}{lrrrrrrr}
\hline Year & $\begin{array}{r}\text { California } \\
\text { Electricity }\end{array}$ & $\begin{array}{r}\text { Vehicle Miles } \\
\text { Traveled } \\
\text { net of Hydro } \\
\text { (Twh) }\end{array}$ & $\begin{array}{r}\text { Gat. Ind. } \\
\text { \& Other } \\
\text { (Billions) }\end{array}$ & $\begin{array}{r}\text { Gasoline } \\
\text { Price } \\
\text { Index }\end{array}$ & $\begin{array}{r}\text { Gross St. } \\
\text { Product } \\
\text { Trillion) }\end{array}$ & $\begin{array}{r}\text { Therm. } \\
\text { Intensity } \\
\text { (tons/ } \\
\text { MWh) }\end{array}$ & $\begin{array}{r}\text { Trans. } \\
\text { (tons } / 1000 \\
\text { Miles) }\end{array}$ \\
\hline \hline & & & & & & & \\
1990 & 146.6 & 259 & 121.7 & 185.22 & 1.42 & 0.495 & 0.543 \\
1991 & 142.8 & 258 & 118.3 & 173.40 & 1.40 & 0.495 & 0.532 \\
1992 & 156.7 & 263 & 112.9 & 176.53 & 1.38 & 0.518 & 0.548 \\
1993 & 137.2 & 266 & 110.9 & 174.50 & 1.38 & 0.581 & 0.528 \\
1994 & 165.3 & 272 & 112.0 & 168.95 & 1.42 & 0.509 & 0.525 \\
1995 & 140.4 & 276 & 110.1 & 168.06 & 1.48 & 0.488 & 0.530 \\
1996 & 133.5 & 278 & 113.2 & 173.60 & 1.53 & 0.511 & 0.534 \\
1997 & 136.1 & 279 & 119.0 & 166.34 & 1.69 & 0.493 & 0.541 \\
1998 & 148.3 & 291 & 123.9 & 146.88 & 1.76 & 0.487 & 0.531 \\
1999 & 152.0 & 300 & 123.5 & 165.96 & 1.86 & 0.508 & 0.530 \\
2000 & 178.0 & 307 & 115.9 & 195.64 & 1.96 & 0.484 & 0.554 \\
2001 & 177.5 & 311 & 113.8 & 184.10 & 1.90 & 0.474 & 0.550 \\
2002 & 155.4 & 322 & 116.2 & 158.35 & 1.93 & 0.464 & 0.554 \\
2003 & 158.0 & 324 & 113.8 & 188.39 & 2.00 & 0.438 & 0.542 \\
2004 & 164.3 & 329 & 117.3 & 206.33 & 2.10 & 0.406 & 0.539 \\
2005 & 161.8 & 329 & 114.3 & 232.51 & 2.18 & 0.400 & 0.545 \\
2006 & 170.0 & 327 & 113.4 & 251.02 & 2.23 & 0.396 & 0.549 \\
2007 & 185.6 & 328 & 109.5 & 273.18 & 2.25 & 0.393 & 0.546 \\
2008 & 184.9 & 327 & 110.1 & 300.09 & 2.20 & 0.387 & 0.516 \\
2009 & 178.7 & 324 & 106.6 & 227.17 & 2.14 & 0.397 & 0.502 \\
2010 & 171.4 & 323 & 111.1 & 259.27 & 2.16 & 0.372 & 0.493
\end{tabular}

and reported by the states, rather than centrally calculated by OHI.

While these data measure on-road VMT, the cap-and-trade program caps emissions from all diesel and gasoline combusted as transportation fuel in California, regardless of whether the fuel is combusted on-road or off-road. To address this potential source of bias we deviate from ARB's emissions categorization of "transportation" by excluding GHG emissions from off-road vehicle activities, in favor of categorizing them into "Natural Gas and Other." Therefore, beginning with total transportation sector combustion emissions, we partition emissions into on-road and off-road activities using the more granular activity-based emissions values reported in the Inventory. The emissions levels reported in Figure 1 in the text reflect this partition of on-road and off-road emissions. The details of this partitioning are further described in Section A.2. Table A.1 presents the data used to estimate the econometric models described below.

\section{A.1.3 Estimation of Cointegrated Vector Autoregression}

Define $Y_{i t}=\ln \left(X_{i t}\right)$ for $i=1,2, \ldots, 7$ and $Y_{t}=\left(Y_{1 t}, Y_{2 t}, \ldots, Y_{7 t}\right)^{\prime}$. In terms of this notation a first-order VAR can be written as

$$
\Theta(L) \cdot Y_{t}=\mu+\epsilon_{t}
$$


where $\mathrm{L}$ is the lag operator which implies, $L^{k} Y_{t}=Y_{t-k}, I$ is a $(7 \times 7)$ identity matrix, $\Theta(L)$ is $(7 \times 7)$ matrix function in the lag operator equal to $(I-\Theta L)$ where $\Theta$ is a $(7 \times 7)$ matrix of constants, $\mu$ is a (7x1) vector of constants, and $\epsilon_{t}$ is a $(7 \times 1)$ white noise sequence with a $(7 \times 1)$ zero mean vector and a $(7 \times 7)$ covariance matrix $\Omega$. In terms of the lag operator notation $(1-L)=\Delta$, so that $\Delta Y_{t}=Y_{t}-Y_{t-1}$.

Model (A.1) allows each element of $Y_{t}$ to be non-stationary (contain a unit root) and exhibit net positive or negative growth over the sample period. A linear time series process that is stationary in first-differences is also called an integrated process with the order of integration equation equal to 1 . In the next subsection, we perform several Dickey and Fuller (1979) tests and two of the Dickey-Fuller GLS tests proposed by Elliott, Rothenberg, and Stock (1996) of the null hypothesis that the time series contains a unit root for each element of $Y_{t}$. All of these tests find little evidence against the null hypothesis that each element of $Y_{t}$ contains a unit root. Diebold and Kilian (2000) present Monte Carlo evidence that the forecasting performance of a univariate AR(1) model can be improved by using a unit root test to determine whether to use the levels or first-difference version of the model. Our unit root tests are consistent with our decision to model the vector $\Delta Y_{t}$ as 2nd-order stationary process.

Diebold and Kilian (2000, p. 287) also argue that "differencing provides insurance against problems due to small-sample bias and explosive roots problems, at a cost." They argue that the problems associated with forecasting future values from an $\mathrm{AR}(1)$ process are most severe for situations with a small number of observations and longer forecast horizons, where the insurance is more than worth the cost. Because our empirical analysis relies on a small number of observations and has a relatively long forecast horizon, this logic provides an additional reason, besides the results of our unit root tests, for specifying our VAR in first-differences.

It is often the case that stationary linear combinations of non-stationary economic time series exist because there are long-run economic relationships between these variables. This logic suggests that there are linear combinations of the elements of $Y_{t}$ that are likely to be 2nd-order stationary in levels. Vectorvalued time series processes whose elements are 2nd-order stationary in first-differences and have stationary linear combinations of the levels of their elements are said to be cointegrated. Engle and Granger (1987) provide a complete discussion of this concept and its implications for the specification and estimation of multivariate linear time series models. For a k-dimensional random vector, $Y_{t}$, with each element stationary in first-differences, the number of distinct stationary linear combinations of the elements of $Y_{t}$ is called the cointegrating rank of the VAR. The cointegrating rank is also equal to the rank of the matrix $\Lambda \equiv-(I-\Theta)$. The existence of cointegrating relationships among elements of $Y_{t}$ imposes restrictions on the elements of $\Lambda$ that will yield more precise estimates of the elements of $\Lambda$ (and $\Theta$ ) and shorter confidence intervals for future values of GHG emissions.

Suppose that the rank of the matrix $\Lambda$ is equal to $r(0<r<7)$. This implies that the following error correction representation exists for $Y_{t}$ :

$$
\Delta Y_{t}=\mu+\Lambda Y_{t-1}+\epsilon_{t}
$$

where $\Lambda=-\gamma \alpha^{\prime}$ for $\gamma$ a $(7 \times \mathrm{r})$ rank $\mathrm{r}$ matrix of parameters and $\alpha$ a $(7 \times \mathrm{r})$ rank $\mathrm{r}$ matrix of parameters. Define the $(\mathrm{r} \times 1)$ vector $Z_{t}=\alpha^{\prime} Y_{t}$ which is composed of the stationary linear combinations of $Y_{t}$. This notation implies that $\Lambda Y_{t-1}$ is equal to $-\gamma Z_{t-1}$.

Johansen (1988) devised a test of the cointegrating rank of a VAR whose elements are 2nd-order stationary in first-differences. We utilize Johansen's (1988) maximum likelihood estimation procedure to recover consistent, asymptotically normal estimates of $\mu, \Omega$, and $\Lambda$ with these co-integrating restrictions imposed. Using these parameter estimates, we then compute an estimate of the joint distribution of $\left(Y_{2013}^{\prime}, Y_{2014}^{\prime}, \ldots, Y_{2020}^{\prime}\right)^{\prime}$ conditional on the value of $Y_{2010}$ that takes into account both our uncertainty in the values of $\mu, \Omega$, and $\Lambda$ because of estimation error and uncertainty due to the fact that $\left(Y_{2013}^{\prime}, Y_{2014}^{\prime}, \ldots, Y_{2020}^{\prime}\right)^{\prime}$ depends on future realizations of $\epsilon_{t}$ for $t=2011, \ldots, 2020$. We then apply the transformation $X_{i t}=\exp \left(Y_{i t}\right)$ to each element 
of $Y_{t}$ to obtain an estimate of the joint distribution of $\left(X_{2013}, X_{2014}, \ldots, X_{2020}\right)$ conditional on the value of $X_{2010} \cdot{ }^{8}$

We employ a two-stage smoothed bootstrap approach to compute an estimate of the distribution of $\left(X_{2013}^{\prime}, X_{2014}^{\prime}, \ldots, X_{2020}^{\prime}\right)^{\prime} .{ }^{9}$ The first step computes an estimate of the joint distribution of the estimates of $\mu, \Omega$, and $\Lambda$ by resampling from the smoothed empirical distribution of the $(7 \times 1)$ vector of residuals from the estimated VAR with the restrictions implied by cointegration imposed. Specifically, let $\hat{\mu}, \hat{\Omega}$, and $\hat{\Lambda}$ equal the estimates of the elements of the VAR imposing the cointegration of rank r restriction that $\hat{\Lambda}=-\hat{\gamma} \hat{\alpha}^{\prime}$. We compute

$$
\hat{\epsilon}_{t}=Y_{t}-\hat{\mu}-\hat{\Lambda}_{1} Y_{t-1}
$$

for $t=1991$ to 2010 . Note that we can only compute values of $\hat{\epsilon}_{t}$ for $t=1991$ to 2010 , because our sample begins in 1990 and the $(t-1)$ th observation is required to compute the value of $\hat{\epsilon}_{t}$ for period $t=1991$. We construct the kernel density estimate of the $\hat{\epsilon}_{t}$ as

$$
\hat{f}(t)=\frac{1}{T h^{7}} \sum_{t=1}^{T} K\left\{\frac{1}{h}\left(t-\hat{\epsilon}_{t}\right)\right\}
$$

where $T$ is the number of observations, $h$ is a user-selected smoothing parameter, and $K(t)$ is a multivariate kernel function that is everywhere positive and integrates to one. We use the multivariate normal kernel

$$
K(x)=\frac{1}{(2 \pi)^{7 / 2}} \exp \left(-\frac{1}{2} x^{\prime} x\right) \quad \text { where } \quad x \in \Re^{7}
$$

and $h=0.5$. Our estimate of the distribution of GHG emissions from 2013 to 2020 is insensitive to the value chosen for $h$, as long as it is less than 1.

We then draw $T=20$ values from (A.4) and use the parameter estimates $(\hat{\mu}, \hat{\Omega}$, and $\hat{\Lambda})$ and these draws to compute re-sampled values of $Y_{t}$ for $t=1,2, \ldots, T=20$. Let $\left(\hat{\epsilon}_{1}^{m}, \hat{\epsilon}_{2}^{m}, \ldots, \hat{\epsilon}_{20}^{m}\right)^{\prime}$ denote the $m$ th draw of the 20 values of $\hat{\epsilon}_{t}$ from $\hat{f}(t)$. We compute the $Y_{t}^{m}$, the 20 resampled values of $Y_{t}$ for $t=1991$ to 2010 , by applying the following equation starting with the value of $Y_{t}$ in $1990\left(Y_{1990}^{m}=Y_{1990}\right.$ for all $\left.m\right)$

$$
Y_{t}^{m}=\hat{\mu}+I+\hat{\Lambda}_{1} Y_{t-1}^{m}+\hat{\epsilon}_{t}^{m} .
$$

We then estimate the values of $\mu, \Omega$, and $\Lambda$ by applying Johansen's (1988) ML procedure using the $Y_{t}^{m}$ and imposing the cointegration rank restriction that $\Lambda=-\gamma \alpha^{\prime}$. Call the resulting estimates $\hat{\mu}^{m}, \hat{\Omega}^{m}$, and $\hat{\Lambda}^{m}$. Repeating this process $M=1000$ times yields the bootstrap distribution of $\hat{\mu}, \hat{\Omega}$, and $\hat{\Lambda}$. This step accounts for the uncertainty in future values of $Y_{t}$ due to the fact that true values of the of $\mu, \Omega$, and $\Lambda$ are unknown and must be estimated.

To account for the uncertainty in $Y_{T+k}$ due to future realizations of $\epsilon_{t}$, for each $m$ and set of values of $\hat{\mu}^{m}$, $\hat{\Omega}^{m}$, and $\hat{\Lambda}^{m}$, we draw $H=10$ values from $\hat{f}(t)$ in equation (A.4), calling these values $\left(\hat{\epsilon}_{T+1}^{m}, \hat{\epsilon}_{T+2}^{m}, \ldots \hat{\epsilon}_{T+H}^{m}\right)^{\prime}$. Using these draws and $\hat{\mu}^{m}, \hat{\Omega}^{m}$, and $\hat{\Lambda}_{1}^{m}$ we compute future values $Y_{T+k}$ for $k=1,2, \ldots, H$ given the actual value of $Y_{T}$ using the following equation:

$$
Y_{T+k \mid T}^{m}=\hat{\mu}^{m}+\left(I+\hat{\Lambda}^{m}\right) Y_{T+k-1 \mid T}^{m}+\hat{\epsilon}_{T+k}^{m} \quad \text { for } \quad k=1,2, \ldots, 10
$$

\footnotetext{
${ }^{8}$ We carried out similar estimation using data through 2012. The procedure was identical, except it was no longer necessary to simulate values for 2011 and 2012 to create simulated values for 2013 through 2020 . For this reason, the confidence intervals for future values of the elements of $X_{t}$ from 2013 to 2020 based on data through 2012 were typically somewhat smaller than those based on data up to 2010. We focus on the results using data through 2010, because those were the data available at the time that final decisions on the market design were made in 2012.

${ }^{9}$ For a discussion of the smoothed bootstrap, see Efron and Tibshirani (1993).
} 
This yields one realization of the future sample path of $Y_{t}$ for $t=2011,2012, \ldots, 2020$. The elements of $Y_{t}$ are then transformed to $X_{t}$ by applying the transformation $X_{i t}=\exp \left(Y_{i t}\right)$ to each element of $Y_{t}$ to yield a realization of the future time path of $X_{t}$. The elements of $X_{t}$ are then transformed to produce a realization of the future time path of GHG emissions by each covered sector from 2011 to 2020, as described in section A.1.5. This two-step process of computing $\hat{\mu}^{m}, \hat{\Omega}^{m}$, and $\hat{\Lambda}^{m}$ and then simulating $Y_{T+k \mid T}^{m}$ for $k=$ $1,2, \ldots, 10$ replicated $m=1$ to $M=1000$ times produces 1,000 realizations from the simulated distribution of $\left(X_{2011}^{\prime}, \ldots, X_{2020}^{\prime}\right)^{\prime}$. Discarding the first two elements of this vector yields a realization from the distribution of $\left(X_{2013}^{\prime}, X_{2014}^{\prime}, \ldots, X_{2020}^{\prime}\right)^{\prime}$ conditional on data through 2010.

We explored a number of alternative approaches to computing the joint distribution $\left(X_{2013}, X_{2014}, \ldots, X_{2020}\right)^{\prime}$. For example, rather than re-sampling from the smoothed distribution of the $\hat{\epsilon}_{t}$, we applied the wild bootstrap to generate the values of $\epsilon_{t}^{\hat{m}}$ used in (A.5) to compute the $Y_{t}^{m}$ for each value of $t$ and $m$ using the procedure recommended by Davidson and Flachaire (2008). In the second step of this approach, we draw the values of $\epsilon_{T+k}$ for $k=1,2, \ldots, 10$ from $\hat{f}(t)$ (equation (A.4)), as described above. The estimated joint distribution of $\left(X_{2011}^{\prime}, \ldots, X_{2020}^{\prime}\right)^{\prime}$ from this procedure was virtually identical to that obtained from the two-step smoothed bootstrap approach.

\section{A.1.4 Unit Root/Cointegration Tests and Estimation of VAR}

This subsection describes the results of the unit root tests for each of the individual elements of the vector $Y_{t}$, the results of the cointegrating rank tests for the vector autoregressive model for $Y_{t}$, and presents the parameter estimates of the VAR model used to estimate the distribution of $\left(X_{2013}^{\prime}, X_{2014}^{\prime}, \ldots, X_{2020}^{\prime}\right)^{\prime}$.

We present three versions of the Dickey-Fuller (DF) unit root tests for each element of $Y_{t}$ and report two test statistics for each hypothesis test and two versions of the Dickey-Fuller GLS (DF-GLS) test proposed by Elliott, Rothenberg and Stock (1996). Let $Y_{i t}$ equal the $i$ th element of $Y_{t}$. The zero mean version of the DF unit root test assumes $Y_{i t}$ follows the model,

$$
Y_{i t}=\alpha Y_{i t-1}+\eta_{i t}
$$

meaning that $Y_{i t}$ is assumed to have a zero mean under both the null and alternative hypothesis. The hypothesis test for this model is $\mathrm{H}: \alpha=1$ versus $\mathrm{K}: \alpha<1$.

In Table A.2 we report two test statistics for this null hypothesis

$$
\hat{\rho}=T(\hat{\alpha}-1) \quad \text { and } \quad \hat{\tau}=\frac{\hat{\alpha}-1}{S E(\hat{\alpha})}
$$

where $\hat{\alpha}$ is the ordinary least squares (OLS) estimate of $\alpha$ and $S E(\hat{\alpha})$ is OLS standard error estimate for $\hat{\alpha}$ from a regression without a constant term and $\mathrm{T}$ is the number of observations in the regression. The column labeled " $\mathrm{Pr}<\hat{\rho}$ " is the probability that a random variable with the asymptotic distribution of $\hat{\rho}$ under the null hypothesis is less than the value of the statistic in the column labeled " $\hat{\rho}$ ". The column labeled " $\operatorname{Pr}<\hat{\tau}$ " is the probability that a random variable with the asymptotic distribution of the $\hat{\tau}$ under the null hypothesis is less than the value of the statistic in the column labeled " $\tau$ ".

The second version of the unit root test assumes a non-zero mean. In this case the assumed model is:

$$
Y_{i t}=\mu+\alpha Y_{i t-1}+\eta_{i t}
$$

where $\mu \neq 0$. The hypothesis test is still $\mathrm{H}: \alpha=1$ versus $\mathrm{K}: \alpha<1$. The two test statistics for this null hypothesis are

$$
\hat{\rho}=T(\hat{\alpha}-1) \quad \text { and } \quad \hat{\tau}=\frac{\hat{\alpha}-1}{S E(\hat{\alpha})}
$$


where $\hat{\alpha}$ is the OLS estimate of $\alpha$ and $S E(\hat{\alpha})$ is OLS standard error estimate for $\hat{\alpha}$ from a regression that includes a constant term and $\mathrm{T}$ is the number of observations in the regression. The test statistics and probability values are reported in the same manner as for the zero mean version of the test statistic.

The third version of the test assumes that the mean of $Y_{i t}$ contains a time trend so that the assumed model is:

$$
Y_{i t}=\mu+\nu t+\alpha Y_{i t-1}+\eta_{i t}
$$

where $\mu \neq 0$ and $\nu \neq 0$. The hypothesis test is still $\mathrm{H}: \alpha=1$ versus $\mathrm{K}: \alpha<1$. The two test statistics for this null hypothesis are again

$$
\hat{\rho}=T(\hat{\alpha}-1) \quad \text { and } \quad \hat{\tau}=\frac{\hat{\alpha}-1}{S E(\hat{\alpha})}
$$

where $\hat{\alpha}$ is the OLS estimate of $\alpha$ and $S E(\hat{\alpha})$ is OLS standard error estimate for $\hat{\alpha}$ from a regression that includes a constant term and a time trend, and $\mathrm{T}$ is the number of observations in the regression. The test statistics and probability values are reported in the same manner as for the zero mean version of the test statistic.

Table A.2 presents the results of these unit root tests for the seven elements of $Y_{t}$. For all three versions of the unit root test and two test statistics, there is little evidence against the unit root null hypothesis for all seven elements of the $Y_{t}$. In all but a few cases, the probability value is greater than 0.05 , which implies no evidence against the null hypothesis for a size 0.05 test of the null hypothesis. Although there are a few instances of probability values less than 0.05 , this is to be expected even if the null hypothesis is true for all of the series, because the probability of rejecting the null given it is true for a 0.05 size test is 0.05 .

The final variable in the first column of this table reports the results of these unit root tests applied to the logarithm of annual broad scope emissions. For this variable, we find little evidence against the null hypothesis of a unit root, which is consistent with this variable being stationary in first-differences.

Table A.3 reports the results of the DF-GLS tests with and without a time trend. The columns with the heading $\hat{\tau}$ contain the values of the test statistic with one lag for the first-differenced or de-trended variable in the DF regression. The columns with the heading " $5 \%$ Critical Value" are the critical values for a size $\alpha=0.05$ test of the null hypothesis of a unit root. The results of the DF-GLS tests are also consistent with each of the elements of $Y_{t}$ having a unit root.

Table A.4 presents the results of our cointegration rank tests for the 1990 to 2010 period. This hypothesis test is formulated in terms of the notation of the error correction version of the cointegrated VAR model:

$$
\Delta Y_{t}=\mu+\Lambda Y_{t-1}+\epsilon_{t}
$$

where $\Lambda$ is $(7 \times 7)$ matrix that satisfies the restriction $\Lambda=-\gamma \alpha^{\prime}$ and $\gamma$ and $\alpha$ are $(7 \mathrm{x} \mathrm{r})$ matrices of rank $\mathrm{r}$. The hypothesis test is $\mathrm{H}: \operatorname{Rank}(\Lambda)=r$ versus $\mathrm{K}: \operatorname{Rank}(\Lambda)>r$, where $\mathrm{r}$ is less than or equal to 7 , the dimension of $Y_{t}$. Each row of Table A.4 presents the results of Johansen's (1988) likelihood ratio test of the null hypothesis that $\operatorname{Rank}(\Lambda)=r$ against the alternative that $\operatorname{Rank}(\Lambda)>r$, for a given value of $\mathrm{r}$. Johansen (1995) recommends a multi-step procedure starting from the null hypothesis that $\operatorname{Rank}(\Lambda)=r=0$ and then proceeding with increasing values of $\mathrm{r}$ until the null hypothesis is not rejected, or all null hypotheses are rejected, in order to determine the rank of $\Lambda$. Rejecting the null hypothesis for all values of $r$ would imply that the elements of $Y_{t}$ are not cointegrated.

The column labelled "LR(r)" is Johansen's (1988) likelihood ratio statistic for the cointegrating rank hypothesis test for the value of $\mathrm{r}$ on that row of the table. The column labelled " $5 \%$ Critical Value" is the upper 5th percentile of the asymptotic distribution of the LR statistic under the null hypothesis. The column labelled "Eigenvalue" contains the second largest to smallest eigenvalue of the estimated value of $\Lambda$. Let $1>\hat{\lambda}_{1}>\hat{\lambda}_{2}, \ldots>\hat{\lambda}_{K}$ equal the eigenvalues of the maximum likelihood estimate of $\Lambda$ ordered from largest to smallest. The $\operatorname{LR}(\mathrm{r})$ statistic for the test $\mathrm{H}: \operatorname{Rank}(\Lambda)=r$ versus $\mathrm{K}: \operatorname{Rank}(\Lambda)>r$ is equal to 
Table A.2: Unit Root Test Statistics (Data from 1990 to 2010)

\begin{tabular}{|c|c|c|c|c|c|}
\hline Variable & Type & $\hat{\rho}$ & $\operatorname{Pr}<\hat{\rho}$ & $\hat{\tau}$ & $\operatorname{Pr}<\hat{\tau}$ \\
\hline ln_twh_p_hydro & Zero Mean & 0.04 & 0.6768 & 0.62 & 0.8405 \\
& Single Mean & -5.18 & 0.3718 & -1.49 & 0.5148 \\
& Trend & -17.14 & 0.0370 & -2.59 & 0.2873 \\
ln_vmt & Zero Mean & 0.04 & 0.6777 & 1.74 & 0.9755 \\
& Single Mean & -1.95 & 0.7666 & -2.15 & 0.2288 \\
& Trend & 0.17 & 0.9928 & 0.05 & 0.9937 \\
ln_ngother_industrial & Zero Mean & -0.01 & 0.6654 & -0.34 & 0.5495 \\
& Single Mean & -14.84 & 0.0136 & -2.49 & 0.1328 \\
ln_real_gas_price & Trend & -16.49 & 0.0469 & -2.52 & 0.3155 \\
& Zero Mean & 0.07 & 0.6851 & 0.80 & 0.8765 \\
In_real_gsp & Single Mean & -2.00 & 0.7609 & -0.74 & 0.8143 \\
& Trend & -9.33 & 0.3785 & -2.13 & 0.4976 \\
& Zero Mean & 0.55 & 0.8045 & 1.00 & 0.9091 \\
& Single Mean & -1.93 & 0.7689 & -1.45 & 0.5360 \\
& Trend & -15.59 & 0.0642 & -1.82 & 0.6543 \\
& Zero Mean & 0.35 & 0.7540 & 1.24 & 0.9384 \\
ln_thermal_intensity & Single Mean & -0.25 & 0.9317 & -0.12 & 0.9335 \\
& Trend & -16.60 & 0.0451 & -3.50 & 0.0680 \\
& Zero Mean & 0.12 & 0.6967 & 0.69 & 0.8551 \\
ln_broad_emissions & Single Mean & -5.39 & 0.3506 & -0.78 & 0.8019 \\
& Trend & -3.66 & 0.8848 & -0.63 & 0.9645 \\
& Zero Mean & 0.005 & 0.7164 & 0.23 & 0.7219 \\
& Single Mean & -2.53 & 0.7098 & -1.19 & 0.6336 \\
& Trend & -1.86 & 0.9651 & -0.54 & 0.9716 \\
\hline
\end{tabular}

Table A.3: DF-GLS Unit Root Test Statistics (Data from 1990 to 2010), Lag=1

\begin{tabular}{|c|c|c|c|c|}
\hline \multirow{3}{*}{$\begin{array}{c}\text { Variable } \\
\text { ln_twh_p_hydro }\end{array}$} & \multicolumn{2}{|r|}{ Time Trend } & \multicolumn{2}{|r|}{ No Time Trend } \\
\hline & & $5 \%$ critical value & & $5 \%$ critical value \\
\hline & -2.807 & \multirow{8}{*}{-3.485} & -1.586 & \multirow{8}{*}{-2.559} \\
\hline$l n \_v m t$ & -1.036 & & -0.732 & \\
\hline ln_ngother_industrial & $\overline{-2.443}$ & & -2.015 & \\
\hline ln_real_gas_price & -1.984 & & -0.834 & \\
\hline ln_real_gsp & -2.181 & & -1.065 & \\
\hline ln_thermal_intensity & -2.418 & & -0.385 & \\
\hline ln_transport_intensity & -1.388 & & -1.249 & \\
\hline ln_broadscope_emissions & -0.948 & & -1.096 & \\
\hline
\end{tabular}

$$
L R(r)=-T \sum_{j=r+1}^{K} \ln \left(1-\hat{\lambda}_{j}\right)
$$


Following Johansen's procedure, we find that the null hypothesis is rejected for $r=0$ and $r=1$, but we do not reject the null hypothesis at a 0.05 level for $r=2$ or for any value larger than 2. According to Johansen's procedure, this sequence of hypothesis testing results is consistent with the existence of 2 stationary linear combinations of the elements $Y_{t}$. We impose these co-integrating restrictions on the parameters of VAR model (A.7) that we estimate to simulate the joint distribution of GHG emissions from 2013 to 2020 . Imposing the restrictions implied by the two cointegrating relationships between the elements of $Y_{t}$ reduces the number of free parameters in the $(7 \times 7)$ matrix $\Lambda$ from 49 to $28(=(7 x 2) x 2)$, the total number of elements in $\gamma$ and $\alpha$. Consistent with the logic that imposing valid restrictions on parameters of a linear regression reduces the variance of the resulting parameter estimates and therefore the variance of prediction errors for the dependent variable, imposing these restrictions on our VAR reduces the variance and size of the pointwise confidence intervals for the time path of GHG emissions from 2013 to 2020.

Table A.4: Cointegration Rank Test Using Trace (Data from 1990 to 2010)

\begin{tabular}{|c|c|c|c|c|}
\hline $\begin{array}{c}\text { H0: } \\
\text { Rank=r }\end{array}$ & $\begin{array}{c}\text { H1: } \\
\text { Rank }>\mathrm{r}\end{array}$ & Eigenvalue & LR(r) & $5 \%$ Critical Value \\
\hline 0 & 0 & 0.9819 & 175.6422 & 123.04 \\
1 & 1 & 0.8253 & 95.4034 & 93.92 \\
2 & 2 & 0.7286 & 60.5073 & 68.68 \\
3 & 3 & 0.5886 & 34.4269 & 47.21 \\
4 & 4 & 0.4416 & 16.6652 & 29.38 \\
5 & 5 & 0.1659 & 5.0110 & 15.34 \\
6 & 6 & 0.0668 & 1.3827 & 3.84 \\
\hline
\end{tabular}


Table A.5 presents the results of estimating our co-integrated VAR model for $Y_{t}$ for the 1990-2010 sample period in terms of the model notation given (A.7). The variable $\Lambda_{i j}$ in Table A.5 is the (i,j) element of $\Lambda$, which also equals $-\gamma \alpha^{\prime}$, and $\mu_{j}$ is the jth element of $\mu$. The model was estimated under the assumption that $\Lambda$ has rank $r=2 .{ }^{10}$ We report the parameter estimates in terms of the elements of $\Lambda$ rather than in terms of $\gamma$ and $\alpha$ because these parameters have the usual (dynamic) linear regression interpretation. As Lutkepohl (1994) and Johansen (2005) emphasize this interpretation does not hold for the coefficients of the cointegrating relationships. Johansen (2005) discusses issue and provides an interpretation for the coefficients of cointegrating relationships.

Under the assumption that a rank $r=2$ cointegrated VAR model is a valid description of the time series properties of $Y_{t}$, the null hypothesis that the 7-dimensional vectors $\epsilon_{t} t=1,2, \ldots, T$ in (A.7) are independent and identically distributed with $E\left(\epsilon_{t}\right)=0$ and $E\left(\epsilon_{t} \epsilon_{t}^{\prime}\right)=\Omega$ should not be rejected. Hosking (1980) derives a multivariate portmanteau statistic that tests the null hypothesis that the disturbances to an M-dimensional vector $\operatorname{ARMA}(\mathrm{p}, \mathrm{q})$ process are independently and identically distributed M-dimensional random vectors with mean zero and an arbitrary positive definite contemporaneous covariance matrix. Under this null hypothesis, the portmanteau test statistic is asymptotically distributed as a chi-squared random variable with $M^{2}(S-p-q)$ degrees of freedom, where $\mathrm{S}$ is the number of sample autocovariance matrices of the vector of residuals from the estimated vector $\operatorname{ARMA}(\mathrm{p}, \mathrm{q})$ model included in the statistic. This statistic reduces to the standard univariate Box and Pierce (1970) statistic for the case that $\mathrm{M}=1$. The first panel of Table A.6 presents the values of the multivariate portmanteau statistic for $S=1,2, \ldots, 5$ for the rank $r=2$ VAR for the 1990 to 2010 sample period. For all values of S, the p-value associated with the value of the test statistic is significantly larger than 0.05 , indicating that a size 0.05 test of the null hypothesis is not rejected.

\footnotetext{
${ }^{10}$ We were concerned about the ability of the Johansen's cointegration testing procedure to detect the rank of $\Lambda$. Therefore we performed the following two Monte Carlo studies to investigate this question. First we took the parameters we estimated for our rank 2 cointegrated VAR (given in Table A.5) and generated 1,000 samples of size 20 from this model assuming the errors were multivariate normally distributed and performed the Johansen testing procedure of finding the smallest value of $r$ for which we did not reject the null hypothesis that the rank of $\Lambda$ matrix was equal to $\mathrm{r}$. We found that for approximately 90 percent of our resamples the procedure found $r=2$ or $r=3$ to be the rank of $\Lambda$. We then took the parameters we estimated from a rank 1 cointegrated VAR and generated 1,000 samples of size 20 from this model assuming the errors were multivariate normally distributed and performed the Johansen testing procedure. For this model we found that for approximately 90 percent of our resamples the procedure found $r=1$ or $r=2$ to be the rank of $\Lambda$. Because our estimate of the distribution of BAU GHG emissions for 2013 to 2020 did not appreciably change between a rank 1, 2, or 3 cointegrated VAR, this Monte Carlo evidence increased our confidence in the usefulness of the Johansen testing procedure for determining the rank of $\Lambda$.
} 
Table A.5: Error Correction Vector Autoregression Parameter Estimates (Data from 1990 to 2010)

\begin{tabular}{|c|c|c|c|c|}
\hline Equation & Parameter & Estimate & $\begin{array}{c}\text { Standard } \\
\text { Error }\end{array}$ & Variable \\
\hline \multirow[t]{8}{*}{$\Delta l n_{-} t w h_{p \_} h y d r o$} & $\mu_{1}$ & 2.05653 & 3.99821 & 1 \\
\hline & $\Lambda_{11}$ & -1.06459 & 0.18122 & $l n_{-} t w h_{-} p_{-} h y d r o_{(t-1)}$ \\
\hline & $\Lambda_{12}$ & 0.18190 & 0.32229 & $l n \_v m t_{(t-1)}$ \\
\hline & $\Lambda_{13}$ & 0.03400 & 0.30741 & ln_ngother_industrial $_{(t-1)}$ \\
\hline & $\Lambda_{14}$ & 0.39485 & 0.15354 & ln_real_gas_price $_{(t-1)}$ \\
\hline & $\Lambda_{15}$ & 0.39086 & 0.21525 & ln_real $l_{-} g p_{(t-1)}$ \\
\hline & $\Lambda_{16}$ & 0.56736 & 0.11427 & ln_thermal_intensity $_{(t-1)}$ \\
\hline & $\Lambda_{17}$ & -0.44487 & 0.09247 & ln_transport_intensity $_{(t-1)}$ \\
\hline \multirow[t]{8}{*}{$\Delta l n_{-} v m t$} & $\mu_{2}$ & 2.59102 & 0.87295 & 1 \\
\hline & $\Lambda_{21}$ & -0.01901 & 0.03957 & $l n_{-} t w h_{-} p_{-} h y d r o_{(t-1)}$ \\
\hline & $\Lambda_{22}$ & -0.20593 & 0.07037 & ln_vmt $t_{(t-1)}$ \\
\hline & $\Lambda_{23}$ & -0.19805 & 0.06712 & ln_ngother_industrial $_{(t-1)}$ \\
\hline & $\Lambda_{24}$ & -0.08705 & 0.03352 & $\ln _{-} r e a l_{-} g a s_{-} p r i c e_{(t-1)}$ \\
\hline & $\Lambda_{25}$ & 0.13422 & 0.04700 & $l_{n} r r e a l_{-} g s p_{(t-1)}$ \\
\hline & $\Lambda_{26}$ & -0.03696 & 0.02495 & ln_thermal_intensity $(t-1)$ \\
\hline & $\Lambda_{27}$ & 0.03228 & 0.02019 & ln_transport_intensity $(t-1)$ \\
\hline \multirow[t]{8}{*}{$\Delta$ ln_ngother_industrial } & $\mu_{3}$ & 5.88351 & 1.88197 & 1 \\
\hline & $\Lambda_{31}$ & -0.13073 & 0.08530 & $l n_{-} t w h_{-} p_{-} h y d r o_{(t-1)}$ \\
\hline & $\Lambda_{32}$ & -0.44123 & 0.15170 & ln_vmt $(t-1)$ \\
\hline & $\Lambda_{33}$ & -0.43607 & 0.14470 & ln_ngother_industrial $_{(t-1)}$ \\
\hline & $\Lambda_{34}$ & -0.16004 & 0.07227 & ln_real_gas_price $_{(t-1)}$ \\
\hline & $\Lambda_{35}$ & 0.32999 & 0.10132 & $l n \_r e a l_{-} g s p_{(t-1)}$ \\
\hline & $\Lambda_{36}$ & -0.03468 & 0.05379 & ln_thermal_intensity $(t-1)$ \\
\hline & $\Lambda_{37}$ & 0.03450 & 0.04353 & ln_transport_intensity $_{(t-1)}$ \\
\hline \multirow[t]{8}{*}{$\Delta l n_{-} r e a l_{-}$gas_price } & $\mu_{4}$ & 14.74227 & 7.83613 & 1 \\
\hline & $\Lambda_{41}$ & -0.06160 & 0.35517 & $l n_{-} t w h_{-} p_{-} h y d r o_{(t-1)}$ \\
\hline & $\Lambda_{42}$ & -1.19080 & 0.63165 & $l_{n \_} v m t_{(t-1)}$ \\
\hline & $\Lambda_{43}$ & -1.13893 & 0.60250 & ln_ngother_industrial $_{(t-1)}$ \\
\hline & $\Lambda_{44}$ & -0.51755 & 0.30093 & 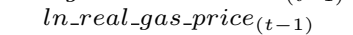 \\
\hline & $\Lambda_{45}$ & 0.75338 & 0.42187 & $l n \_r e a l_{-} g s p_{(t-1)}$ \\
\hline & $\Lambda_{46}$ & -0.23761 & 0.22395 & ln_thermal_intensity $_{(t-1)}$ \\
\hline & $\Lambda_{47}$ & 0.20523 & 0.18123 & ln_transport_intensity $_{(t-1)}$ \\
\hline \multirow[t]{8}{*}{$\Delta l n_{-} r_{e a l} g s p$} & $\mu_{5}$ & 6.73904 & 1.63997 & 1 \\
\hline & $\Lambda_{51}$ & -0.23650 & 0.07433 & $l n_{-} t w h_{-} p_{-} h y d r o_{(t-1)}$ \\
\hline & $\Lambda_{52}$ & -0.47468 & 0.13219 & $l n_{-} v m t_{(t-1)}$ \\
\hline & $\Lambda_{53}$ & -0.48162 & 0.12609 & ln_ngother_industrial $_{(t-1)}$ \\
\hline & $\Lambda_{54}$ & -0.14398 & 0.06298 & $l_{n \_r e a l}{ }_{-} g a s_{-} p r i c e_{(t-1)}$ \\
\hline & $\Lambda_{55}$ & 0.40016 & 0.08829 & ln_real_gsp $(t-1)$ \\
\hline & $\Lambda_{56}$ & 0.01009 & 0.04687 & ln_thermal_intensity $_{(t-1)}$ \\
\hline & $\Lambda_{57}$ & 0.00020 & 0.03793 & ln_transport_intensity $(t-1)_{1}$ \\
\hline \multirow[t]{8}{*}{$\Delta$ ln_thermal_intensity } & $\mu_{6}$ & -2.07239 & 3.67504 & 1 \\
\hline & $\Lambda_{61}$ & 0.26105 & 0.16657 & $l n_{-} t w h_{-} p_{-} h y d r o_{(t-1)}$ \\
\hline & $\Lambda_{62}$ & 0.08335 & 0.29624 & ln_vmt $(t-1)$ \\
\hline & $\Lambda_{63}$ & 0.11318 & 0.28257 & ln_ngother_industrial $_{(t-1)}$ \\
\hline & $\Lambda_{64}$ & -0.03927 & 0.14113 & $l n_{-} r e a l_{-} g a s_{-} p r i c e_{(t-1)}$ \\
\hline & $\Lambda_{65}$ & -0.17368 & 0.19785 & $l n \_r e a l_{-} g s p_{(t-1)}$ \\
\hline & $\Lambda_{66}$ & -0.11032 & 0.10503 & ln_thermal_intensity $_{(t-1)}$ \\
\hline & $\Lambda_{67}$ & 0.08448 & 0.08500 & ln_transport_intensity $_{(t-1)}$ \\
\hline \multirow[t]{8}{*}{$\Delta$ ln_transport_intensity } & $\mu_{7}$ & 1.38462 & 1.63480 & 1 \\
\hline & $\Lambda_{71}$ & -0.07057 & 0.07410 & $l n_{-} t w h_{-} p_{-} h y d r o_{(t-1)}$ \\
\hline & $\Lambda_{72}$ & -0.09104 & 0.13178 & ln_vmt $t_{(t-1)}$ \\
\hline & $\Lambda_{73}$ & -0.09566 & 0.12570 & ln_ngother_industrial $_{(t-1)}$ \\
\hline & $\Lambda_{74}$ & -0.02021 & 0.06278 & 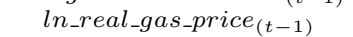 \\
\hline & $\Lambda_{75}$ & 0.08862 & 0.08801 & $l n_{-} r e a l_{-} g s p_{(t-1)}$ \\
\hline & $\Lambda_{76}$ & 0.01440 & 0.04672 & ln_thermal_intensity $_{(t-1)}$ \\
\hline & $\Lambda_{77}$ & -0.00966 & 0.03781 & ln_transport_intensity $_{(t-1)}$ \\
\hline
\end{tabular}


Table A.6: Portmanteau Test Statistics of Model Residuals

\begin{tabular}{|c|c|c|c|}
\hline Model & Lag & Statistic & p-value \\
\hline Rank $=2$ Cointegrated $V A R$ & 1 & 42.3699 & 0.9111 \\
& 2 & 102.8449 & 0.4735 \\
& 3 & 147.1996 & 0.6943 \\
Two Sample Error - Correction Model & 4 & 198.9458 & 0.6084 \\
& 5 & 264.7963 & 0.2707 \\
\hline Bivariate Model & 2 & 8.2422 & 0.5674 \\
& 3 & 26.5808 & 0.3017 \\
& 4 & 40.3913 & 0.5275 \\
& 5 & 50.3961 & 0.2787 \\
\hline & 1 & 0.5815 & 0.9810 \\
& 2 & 2.1195 & 0.9860 \\
& 3 & 5.4634 & 0.9670 \\
& 4 & 7.9841 & 0.9740 \\
& 5 & 14.5774 & 0.8332 \\
\hline
\end{tabular}

\section{A.1.5 Simulating the Distribution of BAU GHG emissions for 2013-2020}

As discussed in the text, California's cap-and-trade program phases in the covered entities in two tranches. Our approach simulates the distribution of BAU emissions from Phase I entities (narrow scope) and Phase II entities (broad scope) over the entire post-sample period. Phase I, in effect during the first compliance period of 2013 and 2014, covers emissions from in-state and imported electricity generation and emissions from large industrial operations. Phase II, in effect for the second and third compliance periods, 2015-2017 and 2018-2020, expands the program to include combustion emissions from transportation fuels and emissions from natural gas and other fuels combusted at residences and small commercial establishments. In order to simulate covered emissions for 2013-2020, we do three transformations of the simulated values from the VAR: (a) parsing GHG emissions from non-electricity natural gas combustion and other industrial emissions between narrow scope and broad scope categories, (b) deriving GHG emissions from in-state electricity generation, and (c) deriving GHG emissions from transportation.

GHG from Non-Electricity Natural Gas Combustion and Other Industrial Processes: We parse $X_{3 t}$ into the portion of these emissions that are and are not covered by the program under the narrow scope during 2013 and 2014. Based on historical data, we assume that 59 percent of these emissions are from industrial processes and natural gas combustion by large industrial sources and are therefore included in narrow scope emissions that are covered by the emissions cap during the first two years of the program. The remaining 41 percent of industrial GHG and other natural gas emissions are included in broad scope emissions that are covered by the program from 2015 through 2020 .

Electricity Sector Emissions: While GHG from Non-Electricity Natural Gas Combustion and Other Industrial Processes $\left(X_{3 t}\right)$ is already in terms of metric tonnes of GHG, in order to obtain the other two components of total GHG emissions covered under the program - electricity generation and transportation we need to transform components of the simulated values. For the realization of the production of electricity in California net of hydroelectric generation in year $t, X_{1 t}$, we subtract the anticipated amount of renewable and nuclear energy produced in year $t$, as discussed below. The remaining residual production is assumed to be provided by thermal generation. This residual amount is multiplied by the thermal intensity, $X_{6 t}$ to derive emissions from in-state electricity generation, which are included in the cap-and-trade program in all years from 2013 to 2020.

Imported electricity is a substantial category of emissions covered under the state's cap-and-trade program, likely to constitute more than 10 percent of total emissions. However, due to the physics governing 
the operation of an integrated electricity grid, it is impossible to partition aggregate GHG emissions from generation units outside California into those caused by electricity imports into California and those caused by serving electricity demand outside of California. Hobbs, Bushnell, and Wolak (2010) and Bushnell, Chen, and Zaragoza-Watkins (2014) discuss this issue and its implications for the design of the California market for GHG emissions. Consequently, GHG emissions from electricity imports deemed to be covered by the cap-and-trade program are determined largely by an administrative process set by ARB.

Historically, the specific energy deemed to be "delivered" to California is the result of the financial contracting decisions of the importing firm, not the result of the actual flows of electrical energy into the state. Specifically, coal-fired electricity would be deemed to be "delivered" to California because a coal-fired power plant outside of California contracted with a buyer in California to supply electricity. The incentive of California load-serving entities to claim electricity from GHG emissions-intensive sources is "delivered" to California changes dramatically with the introduction of a cap-and-trade program that puts a price on GHG emissions from electricity imports. Consequently, claimed GHG annual emissions from electricity imports from 1990 to 2010 are unlikely to be informative about claimed emissions from electricity imports during the cap-and-trade program. For these reasons, we do not include GHG emissions from electricity imports in any of our models for BAU emissions. We instead use the administratively determined value for GHG emissions from electricity imports from ARB's MRR for 2012 of 40.17 MMT and adjust this value for our estimated amount of reshuffling and other changes in imports during that year.

Transportation Emissions: We calculate transportation emissions much the same way as electricity sector emissions. Both total VMT $\left(X_{2 t}\right)$ and the emissions intensity of VMT $\left(X_{7 t}\right)$ are simulated for the years 2015-2020, the years in which transportation emissions are covered by the cap-and-trade program. For each of the 1000 simulated paths of the VAR variables, these two simulated values are multiplied together to yield an annual value for transportation emissions.

Adding together the emissions for each of the three sectors gives the simulated annual total covered GHG emissions. Summing these annual simulated emissions for the years 2013-2020 produces the simulated aggregate GHG emissions over the life of the program. By carrying out 1000 simulations, as described above, we derive an estimate of the distribution of BAU GHG emissions from 2013 to 2020.

\section{A.1.6 Alternative Approaches to Modelling BAU Emissions}

In order to assess the sensitivity of our estimate of the joint distribution of annual GHG emissions for 2013 to 2020 to our modeling assumptions, this section considers three alternative methodologies for recovering an estimate of this distribution.

\section{A.1.6.1 Two-Sample Error Correction Model}

The first alternative methodology utilizes a two-equation model that takes advantage of the availability of a longer time series for the four non-GHG emissions-related variables in the VAR. This approach first estimates a cointegrated vector autoregression for the four non-GHG emissions variables on a sample that starts in 1975 and ends in 2010. Let $Z_{t}=\left(Y_{1 t}, Y_{2 t}, Y_{4 t}, Y_{5 t}\right)^{\prime}$ equal this 4-dimensional vector. Then a three-variable model using $E_{t}=\left(Y_{2 t}, Y_{5 t}, Y_{6 t}\right)^{\prime}$ with the contemporanous first-difference of $Z_{t}$ as a vector of covariates and an error correction term is estimated.

Variables that start in 1990 are:

$\exp \left(E_{1 t}\right)=$ GHG from Non-Electricity Natural Gas Combustion and Other Industrial Processes (MMT)

$\exp \left(E_{2 t}\right)=$ Emissions Intensity of In-State Thermal Gen. (Metric Tonnes/MWh)

$\exp \left(E_{3 t}\right)=$ Emissions Intensity of VMT (Metric Tonnes/Thousand Miles) 
Variables that start in 1975 are:

$\exp \left(Z_{1 t}\right)=\mathrm{CA}$ electricity production net of hydroelectric generation (TWh)

$\exp \left(Z_{2 t}\right)=$ Total VMT (Thousands of Miles)

$\exp \left(Z_{3 t}\right)=$ Real Retail Gasoline Price Index

$\exp \left(Z_{4 t}\right)=$ Real Gross State Product $(\$ 2015)$

Consistent with the unit-root test results presented in subsection A.1.4, the first difference of $Y_{t}$ and $Z_{t}$ are each assumed to be 2 nd-order stationary. We model $\Delta Z_{t}$ from 1976 to 2010 as a cointegrated VAR process:

$$
\Delta Z_{t}=\nu+\Pi Z_{t-1}+\eta_{t} .
$$

Table A.7 presents the results of Johansen's test for the cointegrating rank for $\Pi$ for the sample period 1975 to 2010. The results of this testing procedure are consistent with assuming that the $4 \times 4$ matrix $\Pi$ is rank 1. The size 0.05 test of the null hypothesis that $r=0$ is rejected, but the null hypothesis is not rejected for $r \geq 1$. We then apply Johansen's maximum likelihood procedure to estimate $\nu, \Pi$ and the covariance matrix of $\eta_{t}$ in (A.8).

We model $\Delta E_{t}$ from 1991 to 2010 as an error-correction model treating $\Delta Z_{t}$ as a vector of pre-determined regressors and include an error correction term in each equation, as shown in (A.9).

$$
\Delta E_{t}=\mu+\phi w_{t-1}+\Gamma \Delta Z_{t}+\epsilon_{t}
$$

where $w_{t}=\beta^{\prime} Y_{t}$ is the stationary linear combination of the seven elements of $Y_{t}$ implied by our earlier hypothesis-testing result that the elements of $Y_{t}$ are cointegrated. There are two possible reasons that this two-sample model could lead to a more precise estimate of the joint distribution of GHG emissions from 2013 to 2020. First, as noted above, our estimates of the parameters of (A.8) take advantage of a significantly longer time series on $Z_{t}$. Second, we include $\Delta Z_{t}$ in (A.9) as opposed to $\Delta Z_{t-1}$ in the equations to predict the elements of $E_{t}$ as is the case for model (A.2) presented in section A.1.3.

We first estimate the elements of $\beta$ by a least squares regression of one element of $Y_{t}$ on the remaining six elements of $Y_{t}$ and estimating $w_{t}$ as the residual from this regression as recommended by Engle and Granger (1987). Because, as noted in Engle and Granger (1987), $T^{1-\delta}(\hat{\beta}-\beta)$ converges in probability to zero for $\delta>0$, we condition our estimate of the distribution of future GHG emissions on this value $\beta$. We then apply OLS to each of the three equations of (A.9) to compute estimates $\hat{\mu}, \hat{\phi}$ and $\hat{\Gamma}$.

We then compute

$$
\hat{\eta}_{t}=\Delta Z_{t}-\hat{\nu}-\hat{\Pi} Z_{t-1}
$$

for $t=1976$ to 2010 and

$$
\hat{\epsilon}_{t}=\Delta E_{t}-\hat{\mu}-\hat{\phi} w_{t-1}-\hat{\Gamma} \Delta Z_{t}
$$

for $t=1991$ to 2010 .

Next we construct 1,000 realizations of the future sample path of $Y_{t}$ and $Z_{t}$ for $t=2011,2012, \ldots, 2020$ given $Z_{T}, Z_{T-1}$, and $Y_{T}$ using the following procedure. Because of the longer time series available to estimate the parameters of (A.8), we do not account for the estimation error in the parameters of (A.8) in estimating the distribution of $Z_{t}$ for 2011 to 2020. Our estimates of the uncertainty in future values of the elements of $Z_{t}$ only depend on our uncertainty about future values of $\eta_{t}$.

We then follow the smoothed bootstrap procedure described in section A.1.3 applied to (A.9) to estimate the distribution $E_{t}$ for 2013 to 2020 conditional on the actual values of $Z_{t}$ in 2009 and 2010 and simulated values of $Z_{t}$ for 2011 to 2020 . This procedure accounts for estimation error in $\mu, \phi$, and $\Gamma$ as well as the uncertainty in future values of $\epsilon_{t}$ in (A.9). Each of the 1,000 realizations of the future sample paths of $\Delta Z_{t}$ 
are fed into the simulation of each of the 1,000 future sample paths of $\Delta E_{t}$, which yields 1,000 realizations of the future sample path of $Y_{t}$ from 2011 to 2020. We apply the transformations described earlier to the simulated values of $Y_{t}$ from 2013 to 2020 to produce our estimates of the distribution of future GHG emissions by each covered sector for this time period.

Table A.8 presents the maximum likelihood estimates of the parameters of (A.8). Table A.9 presents the OLS estimates of the parameters of cointegrating regression $\hat{\beta}$. Table A.10 presents the OLS estimates of the parameters of (A.9). The second panel of Table A.6 presents multivariate portmanteau statistics for the residuals from estimating (A.9). For all values of S, a size 0.05 test of the null hypothesis that $\epsilon_{t}$ from (A.9) is white noise cannot be rejected.

Table A.7: Cointegration Rank Test Using Trace (Data from 1975 to 2010)

\begin{tabular}{|c|c|c|c|c|}
\hline $\begin{array}{c}\text { H0: } \\
\text { Rank=r }\end{array}$ & $\begin{array}{c}\text { H1: } \\
\text { Rank }>\mathrm{r}\end{array}$ & Eigenvalue & LR(r) & $5 \%$ Critical Value \\
\hline 0 & 0 & 0.7061 & 63.3803 & 47.8564 \\
1 & 1 & 0.2905 & 20.5214 & 29.7976 \\
2 & 2 & 0.1845 & 8.5080 & 15.4948 \\
3 & 3 & 0.0384 & 1.3688 & 3.8415 \\
\hline
\end{tabular}

Note: The Johansen cointegration test of (ln_twh_p_hydro, ln_vmt, ln_real_gas_price, ln_real_gsp) from 1975 to 2010 shows that it is of rank 1.

Table A.8: Cointegrated Vector Autoregression Parameter Estimates for $Z_{t}$ from 1975 to 2010)

\begin{tabular}{|c|c|c|c|c|}
\hline Equation & Parameter & Estimate & $\begin{array}{c}\text { Standard } \\
\text { Error }\end{array}$ & Variable \\
\hline \multirow[t]{5}{*}{$\Delta l n_{-} t w h \_p \_h y d r o$} & $\nu_{1}$ & 6.6052 & 1.3873 & 1 \\
\hline & $\Pi_{11}$ & -0.4985 & 0.1050 & $l n_{-} t w h_{-} p_{-} h y d r o_{(t-1)}$ \\
\hline & $\Pi_{12}$ & -0.4243 & 0.0894 & ln_vmt $t_{(t-1)}$ \\
\hline & $\Pi_{13}$ & -0.3870 & 0.0815 & $\ln _{-} r e a l_{-} g a s_{-} p_{r i c e}(t-1)$ \\
\hline & $\Pi_{14}$ & 0.6244 & 0.1316 & $l_{n}{ }_{-} r e a l_{-} g s p_{(t-1)}$ \\
\hline \multirow[t]{5}{*}{$\Delta l n \_v m t$} & $\nu_{2}$ & 1.137 & 0.3039 & 1 \\
\hline & $\Pi_{21}$ & -0.0842 & 0.0230 & $l n_{-} t w h_{-} p_{-} h y d r o_{(t-1)}$ \\
\hline & $\Pi_{22}$ & -0.0716 & 0.0196 & $l n_{-} v m t_{(t-1)}$ \\
\hline & $\Pi_{23}$ & -0.0653 & 0.0179 & ln_real_gas_price $_{(t-1)}$ \\
\hline & $\Pi_{24}$ & 0.1054 & 0.0288 & $l n \_r e a l_{-} g s p_{(t-1)}$ \\
\hline \multirow[t]{5}{*}{$\Delta l n_{-} r e a l_{-} g a s_{-} p r i c e$} & $\nu_{3}$ & 1.1672 & 1.4108 & 1 \\
\hline & $\Pi_{31}$ & -0.0879 & 0.1068 & $l n_{-} t w h_{-} p_{-} h y d r o_{(t-1)}$ \\
\hline & $\Pi_{32}$ & -0.0748 & 0.0909 & $l n_{-} v m t_{(t-1)}$ \\
\hline & $\Pi_{33}$ & -0.0682 & 0.0829 & $l_{n}{ }_{-} e a l_{-} g a s_{-} p r i c e_{(t-1)}$ \\
\hline & $\Pi_{34}$ & 0.1101 & 0.1338 & $l n_{-} r e a l_{-} g s p_{(t-1)}$ \\
\hline \multirow[t]{5}{*}{$\Delta l n_{-} r e a l_{-} g s p$} & $\nu_{4}$ & 1.7665 & 0.3104 & 1 \\
\hline & $\Pi_{41}$ & -0.1317 & 0.0235 & $l n_{-} t w h_{-} p_{-} h y d r o_{(t-1)}$ \\
\hline & $\Pi_{42}$ & -0.1121 & 0.0200 & $l n \_v m t_{(t-1)}$ \\
\hline & $\Pi_{43}$ & -0.1022 & 0.0182 & ln_real_gas_price $_{(t-1)}$ \\
\hline & $\Pi_{44}$ & 0.1649 & 0.0294 & $l n_{-} r e a l_{-} g s p_{(t-1)}$ \\
\hline
\end{tabular}

Note: Rank 1 error correction vector autoregression estimates of (ln_twh_p_hydro, ln_vmt, ln_real_gas_price, ln_real_gsp $)$ from 1975 to 2010 . 
Table A.9: OLS Estimates of Parameters of Cointegrating Vector (Data from 1990 to 2010)

\begin{tabular}{|c|c|c|c|}
\hline Equation & Parameter & Estimate & Variable \\
\hline ln_ngother_industrial & $\beta_{0}$ & 11.947 & 1 \\
& $\beta_{1}$ & -0.0748 & ln_thermal_intensity \\
& $\beta_{2}$ & 0.2844 & ln_transport_intensity \\
& $\beta_{3}$ & -0.0424 & ln_twh_p_hydro \\
& $\beta_{4}$ & -1.0858 & ln_vmt \\
& $\beta_{5}$ & -0.1974 & ln_real_gas_price \\
& $\beta_{6}$ & 0.6085 & ln_real_gsp \\
\hline
\end{tabular}

Table A.10: Error Correction Model Parameter Estimates (Data from 1990 to 2010)

\begin{tabular}{|c|c|c|c|c|}
\hline Equation & Parameter & Estimate & $\begin{array}{c}\text { Standard } \\
\text { Error }\end{array}$ & Variable \\
\hline \multirow[t]{6}{*}{$\Delta l n \_n g o t h e r \_i n d u s t r i a l$} & $\mu_{1}$ & -0.0110 & 0.0045 & 1 \\
\hline & $\Gamma_{11}$ & -0.0196 & 0.0406 & $\Delta l n_{-} t w h_{-} p_{-} h y d r o_{(t)}$ \\
\hline & $\Gamma_{12}^{11}$ & -0.3230 & 0.2707 & $\Delta l n_{-} v m t_{(t)}$ \\
\hline & $\Gamma_{13}$ & -0.0859 & 0.0333 & $\Delta l n_{-} r e a l_{-} g a s_{-} p r i c e_{(t)}$ \\
\hline & $\Gamma_{14}^{10}$ & 0.5274 & 0.1209 & $\Delta n_{n} r e a l_{-} g s p_{(t)}$ \\
\hline & $\phi_{1}$ & -0.9792 & 0.1507 & $w_{(t-1)}$ \\
\hline \multirow[t]{6}{*}{$\Delta$ ln_thermal_intensity } & $\mu_{2}$ & -0.0081 & 0.0137 & 1 \\
\hline & $\Gamma_{21}$ & -0.2327 & 0.1244 & $\Delta l n_{-} t w h \_p \_h y d r o_{(t)}$ \\
\hline & $\Gamma_{22}^{21}$ & 0.4686 & 0.8288 & $\Delta l n_{-} v m t_{(t)}$ \\
\hline & $\Gamma_{23}$ & 0.0149 & 0.1020 & $\Delta l n_{-} r e a l_{-} g a s_{-} p r i c e_{(t)}$ \\
\hline & $\Gamma_{24}$ & -0.4616 & 0.3701 & $\Delta l n \_r e a l_{-} g s p_{(t)}$ \\
\hline & $\phi_{2}$ & 0.1855 & 0.4613 & $w_{(t-1)}$ \\
\hline \multirow[t]{6}{*}{$\Delta l n_{-}$transport_intensity } & $\mu_{3}$ & -0.0146 & 0.0051 & 1 \\
\hline & $\Gamma_{31}$ & 0.0275 & 0.0464 & $\Delta l n_{-} t w h_{-} p_{-} h y d r o_{(t)}$ \\
\hline & $\Gamma_{32}$ & 0.3359 & 0.3095 & $\Delta l n_{-} v m t_{(t)}$ \\
\hline & $\Gamma_{33}$ & 0.0127 & 0.0381 & $\Delta \ln _{-} r e a l_{-} g a s_{-} p r i c e_{(t)}$ \\
\hline & $\Gamma_{34}$ & 0.2787 & 0.1382 & $\Delta l n_{-} r e a l_{-} g s p_{(t)}$ \\
\hline & $\phi_{3}$ & 0.3826 & 0.1723 & $w_{(t-1)}$ \\
\hline
\end{tabular}

Note: Vector autoregression estimates of (ln_ngother_industrial, ln_thermal_intensity, ln_transport_intensity) from 1990 to 2010 with $w_{(t-1)}$, the residual from cointegrating regression, and $\Delta Z_{t}$ as regressors.

\section{A.1.6.2 Bivariate Model}

Our second alternative approach to simulating the distribution of future GHG emissions employs a cointegrated bivariate vector autoregression for broad scope and narrow scope GHG emissions from 1990 to 2010. This model assumes that each element of the vector

$$
D_{t}=\left(\text { logarithm of broad scope emissions }_{t} \text {, logarithm of narrow scope emissions }\right)^{\prime}
$$

are difference stationary and follow a cointegrated bivariate vector autoregressive process. Table A.11 presents the results of Johansen's test for the cointegrating rank applied to this bivariate time series. These testing results are consistent with a rank 1 process. Table A.12 presents the results of applying Johansen's maximum likelihood procedure to the model:

$$
\Delta D_{t}=\mu+\Lambda D_{t-1}+\Gamma \Delta D_{t-1}+\epsilon_{t}
$$

The third panel of Table A.6 presents the multivariate portmanteau statistics for the residuals from (A.10). For all values of $\mathrm{S}$, a size 0.05 test of the null hypothesis that $\epsilon_{t}$ from (A.10) is white noise cannot be rejected.

We then follow our two-step smoothed bootstrap procedure to construct 1,000 simulations of the future time path of broad scope and narrow scope emissions that accounts for both estimation error in $\mu, \Lambda$ and $\Gamma$ and uncertainty in the future values of $\epsilon_{t}$ in (A.10). 
Table A.11: Cointegration Rank Test Using Trace (Data from 1990 to 2010)

\begin{tabular}{|c|c|c|c|c|}
\hline $\begin{array}{c}\text { H0: } \\
\text { Rank=r }\end{array}$ & $\begin{array}{c}\text { H1: } \\
\text { Rank }>\text { r }\end{array}$ & Eigenvalue & LR(r) & $5 \%$ Critical Value \\
\hline 0 & 0 & 0.5170 & 17.8414 & 15.4948 \\
1 & 1 & 0.1515 & 3.2868 & 3.8415 \\
\hline
\end{tabular}

Note: The Johansen cointegration test of (ln_narrowscope_emissions, ln_broadscope_emissions) from 1990 to 2010 with $\operatorname{lag} 0$.

Table A.12: Bivariate Model Parameter Estimates (Data from 1990 to 2010)

\begin{tabular}{|c|c|c|c|c|}
\hline Equation & Parameter & Estimate & $\begin{array}{c}\text { Standard } \\
\text { Error }\end{array}$ & Variable \\
\hline$\Delta$ ln_broadscope_emissions & $\mu_{1}$ & -2.768 & 0.51791 & 1 \\
& $\Lambda_{11}$ & 1.0071 & 0.18821 & In_broadscope_emissions $(t)$ \\
& $\Lambda_{12}$ & -0.60412 & 0.1129 & ln_narrowscope_emissions $(t)$ \\
& $\Gamma_{11}$ & -0.98467 & 0.29891 & $\Delta$ ln_broadscope_emissions $(t-1)$ \\
& $\Gamma_{12}$ & 0.25179 & 0.1075 & $\Delta$ ln_narrowscope_emissions $s_{(t-1)}$ \\
\hline ln_narrowscope_emissions & $\mu_{2}$ & -7.27 & 1.1675 & 1 \\
& $\Lambda_{21}$ & 2.6434 & 0.42427 & ln_broadscope_emissions $(t)$ \\
& $\Lambda_{22}$ & -1.5857 & 0.25451 & ln_narrowscope_emissions $(t)$ \\
& $\Gamma_{21}$ & -2.2024 & 0.67383 & $\Delta$ ln_broadscope_emissions $s_{(t-1)}$ \\
& $\Gamma_{22}$ & 0.66588 & 0.24232 & $\Delta$ ln_narrowscope_emissions $s_{(t-1)}$ \\
\hline
\end{tabular}

\section{A.1.6.3 Sampling with Replacement}

These econometric model-based approaches to simulating the distribution of BAU GHG emissions may be seen by some as imposing excessive structure on such a short time series of data. ${ }^{11}$ To examine the robustness of this approach, our third alternative approach is a bare bones bootstrap GHG forecast method that draws narrow scope and broad scope GHG emissions growth rates for each year from the distribution of these emissions growth rates over the sample period 1990-2010. We created 1,000 bootstrap GHG emissions paths, all starting at the observed 2010 value and then for each successive year drew with replacement from the 20 annual growth rates through 2010. ${ }^{12}$ This approach is equivalent to assuming a bivariate random walk with drift for the logarithm of emissions as given in (A.10) with the value of the two-dimensional vector $\mu$ set equal to the sample mean growth rate of narrow scope and broad scope GHG emissions, respectively. We then constructed a total 2013-2020 covered emissions simulation for each of the 1000 simulations by summing the resulting narrow scope emissions for 2013 and 2014 with the resulting broad scope emissions for 2015-2020. This approach is likely to understate the uncertainty in the distribution of future emissions both because it ignores any serial correlation in growth rates and because it fails to account for the estimation error in $\mu$. That is, it ignores the second source of uncertainty discussed at the beginning of this section uncertainty in the true values of the parameters of distribution of BAU GHG emissions - but given that it assumes the parameters of the distribution are known, it does account for uncertainty in the future values of the unobservables driving the data generation process.

\footnotetext{
${ }^{11}$ There is also a broader concern that this is a very short time series on which to forecast up to a decade of future emissions. We agree wholeheartedly, but the fact is that such data are representative of the information on which policy makers must make decisions on GHG emissions caps.

${ }^{12}$ Each draw was a pair (narrow scope growth, broad scope growth) with the two components taken from the same year so there is consistency between the two series.
} 


\section{A.1.6.4 Results of Alternative Methods for Forecast of BAU GHG Distribution}

Means of the estimated distributions of annual broad scope emissions from 2013 to 2020 for each of the four modeling approaches are shown below Figure A.1. The dotted lines are the pointwise 95 percent upper and lower confidence bands on the future values of annual broad scope emissions.

There is substantial agreement across the four approaches in the estimated means of the distribution of annual broad scope emissions. The four approaches differ somewhat in the size of the pointwise 95 percent confidence intervals. The resampling model has the smallest confidence intervals, likely due to the fact that it does not account for uncertainty in the parameters of the true data generating process. The two-sample error correction model has the largest confidence intervals, likely due to the fact this model involves estimating the largest number of parameters and the contribution of uncertainty in value of these parameters is sufficiently large to relative to the uncertainty in the values of the parameters of the other three more parsimonious models.
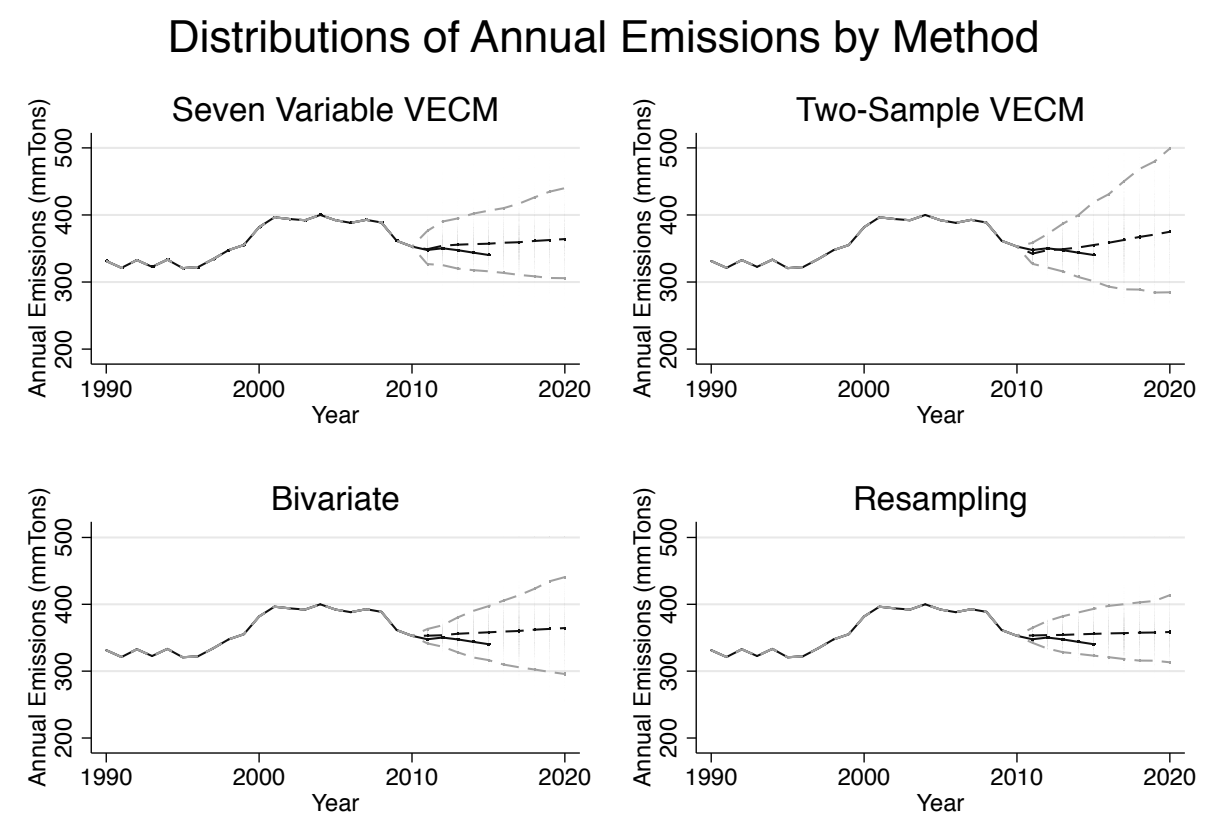

Solid line shows actual values

Figure A.1: Forecast Results - Annual Broad Scope Emissions 


\section{A.2 Abatement Supply}

This section describes the component pieces of the abatement supply function. Abatement derives both from complementary and other policies that produce emissions reductions independent of the allowance price ("Price Non-Responsive Abatement") and from abatement undertaken in response to changes in the allowance price ("Price-Responsive Abatement"). The emissions reductions resulting from these sources are summarized in Table 4 in the main text. Here we describe the assumptions behind each source of abatement.

Much of California's greenhouse gas policy was in flux during 2010-2012, making it difficult to identify exactly when aspects of the complementary policies became "expected" regulations. Rather than attempting to parse exact dates or believed probabilities, we assume that the major programs set in law by 2013 - the Corporate Average Fuel Economy Standard (CAFE), energy efficiency (EE), the Low Carbon Fuel Standard (LCFS) and the 33 percent Renewables Portfolio Standard (RPS) - were anticipated at the time for which we simulate distributions of outcomes. While ARB forecasted GHG reductions from these complementary policies, it is unclear, especially in the out years, how ARB's baseline GHG emissions forecast, from which they estimated GHG reductions, compares to the simulations we obtain from the VAR. Thus, rather than incorporating potentially biased estimates of GHG reductions, we apply a range of adjustments to the quantity of renewable electricity generation and the emissions intensity of VMT, which approximate the range of likely impacts of these complementary policies.

As discussed at the beginning of section $\mathrm{V}$ of the text, we assume that abatement effects are drawn independently from BAU emissions, but there is a mechanical correlation that results from the fact that abatement in transportation and electricity generation manifests as reduced emissions intensity of these activities. We have also experimented with imposing positive correlation among the abatement paths, but these have very small impact on the probability of an interior solution. Even a correlation of 0.5 among all of the abatement paths changes the probability of an interior solution by less than 0.5 percentage points.

As is clear from the discussion below, there is significant uncertainty about the impact of the price non-responsive abatement pathways. It is important to note, however, that these uncertainties affect the distribution of emissions apart from the cap-and-trade program, but do not affect the range of abatement available from the cap-and-trade program. As a result, while any bias in our range of possible impacts from the price non-responsive abatement pathways would shift the distribution of emissions, it would not substantially change the abatement that cap-and-trade could deliver. Thus, it would not impact the slope of the abatement supply curve.

For most policies described below, we assume that abatement will fall within a specific range between a more effective abatement case and a less effective abatement case. We then sample from a symmetric $\beta(2,2)$ distribution to create a random draw of abatement for each policy from within our assumed range.

\section{A.2.1 Price Non-Responsive Abatement}

This section discusses in more detail the sources of price non-responsive abatement (complementary policies and other exogenous drivers) for which we adjust the VAR output to arrive at estimated distributions of emissions quantities and prices. Policies producing price non-responsive abatement include policies targeting both in-state and imported electricity generation, automotive fuel-economy standards, low-carbon fuel standards, and emissions offsets.

\section{A.2.1.1 In-State Electric Generation}

The VAR estimation and simulation procedure described in the text and above produces a draw from the distribution of in-state electricity generation in TWh. We adjust in-state generation to account for two types of zero-carbon electricity generation: renewables and nuclear power. We subtract the assumed energy produced from these zero-carbon sources from the specific realization of in-state electricity generation before 
Table A.13: Drivers of Price Non-responsive Abatement

\begin{tabular}{|c|ccccc|}
\hline & \multicolumn{2}{|c|}{ Zero-Carbon Power } & \multicolumn{2}{c|}{ Transport Intensity } \\
\hline Year & $\begin{array}{c}\text { BAU RPS } \\
\text { GWh }\end{array}$ & $\begin{array}{c}33 \% \text { RPS } \\
\text { GWh }\end{array}$ & $\begin{array}{c}\text { Nuclear } \\
\text { GWh }\end{array}$ & $\begin{array}{c}\text { BAU } \\
\text { Forecast }\end{array}$ & $\begin{array}{c}\text { Raw } \\
\text { EMFAC }\end{array}$ \\
\hline \hline 2013 & 34300 & 39463 & 17342 & 0.487 & 0.470 \\
2014 & 34300 & 44625 & 17342 & 0.485 & 0.461 \\
2015 & 34300 & 49788 & 17342 & 0.483 & 0.450 \\
2016 & 34300 & 54950 & 17342 & 0.481 & 0.433 \\
2017 & 34300 & 60113 & 17342 & 0.479 & 0.416 \\
2018 & 34300 & 65275 & 17342 & 0.478 & 0.399 \\
2019 & 34300 & 70438 & 17342 & 0.475 & 0.383 \\
2020 & 34300 & 75600 & 17342 & 0.473 & 0.366 \\
\hline
\end{tabular}

multiplying the remainder by the estimated GHG emissions intensity of thermal generation to calculate GHG emissions from in-state electric generation. Our BAU scenario assumes renewables generation meets the 20 percent RPS standard that was in place well in advance of the cap-and-trade program. Specific values come from the Statewide Annual Planning Renewable Net Short (RNS) update, ${ }^{13}$ which is produced by the California Energy Commission. The 2011 RNS update provides a forecast of the amount of in-state renewable generation that would be needed to comply with the state's pre-existing 20 percent Renewable Portfolio Standard (RPS) commitment, including adjustments for exempted sales, energy efficiency, and imported renewable energy. The assumed BAU nuclear generation incorporates the closing of the SanOnofre Nuclear Generating Station (SONGS). ${ }^{14}$ We assume that Diablo Canyon (the only remaining nuclear generation station in California) generates electricity equivalent to its 2001-2010 average, which we calculate from EIA data. The nuclear generation and renewable energy necessary to comply with the 20 percent RPS is considered part of our BAU emissions calculation. The exact output assumed for these sources is presented in Table A.13.

\section{A.2.1.2 Zero-Carbon Electricity Generation and Energy Efficiency}

In April 2011 California adopted a 33 percent RPS. ${ }^{15}$ We consider this more stringent target to be a complementary policy providing abatement beyond BAU. The state now seems very likely to exceed the 33 percent level by 2020, but we do not make further adjustments as it was not clear in 2012 how difficult attaining the 2020 standard would be. The 2011 RPS update (described above) forecasts that an additional $41.3 \mathrm{TWh}$ of in-state renewable generation would be needed to comply with the 33 percent RPS. We assume that the State will meet the 33 percent RPS target by incrementally increasing renewables by an equal quantity each year during the 2013-2020 time period. To account for uncertainty in load growth and other factors that could contribute to the State exceeding or failing to meet this target, we draw random scaling factors from a $\beta(2,2)$ distribution with a lower bound of 0.9 and an upper bound of 1.1, which we multiply by cumulative

\footnotetext{
${ }^{13}$ See http://www.energy.ca.gov/2011publications/CEC-200-2011-001/CEC-200-2011-001-SF.pdf

${ }^{14}$ For three decades prior to the opening of California's cap-and-trade program, nuclear power was the largest contributor of zero-emissions electricity generation, coming from Diablo Canyon Nuclear Power Plant and SONGS. In January 2012, SONGS was shut down due to faulty upgrades that had been made in 2009 and 2010, and there was widespread speculation about when and whether it would reopen. In June 2013, Southern California Edison announced that the SONGS closure would be permanent. Even though the official announcement came in June 2013, this outcome was known to be the most likely outcome by mid-2012. For that reason, we assume it was known for the purposes of our analysis.

${ }^{15}$ In 2015, California adopted a new target of 50 percent by 2030, but this did not change the target for 2020.
} 
expected GHG abatement. More formally, realization-specific abatement from the 33 percent RPS in year $T+k$ can be expressed as:

$$
\text { Abatement }_{m, T+k}=\beta_{m}\left(R P S \_T W h_{T+k} \cdot E I_{m, T+k}\right),
$$

where $\beta_{m}$ is the random draw from the $\beta(2,2)$ distribution (which is applied in each of the eight years) associated with simulation draw $m, R P S \_T W h$ is the value of (additional to BAU) renewable TWh in year $T+k$ and $E I_{m, T+k}$ is the realization of emissions intensity for thermal generation in California for simulation draw $m$.

We make no further adjustments to the VAR forecast to account for increased energy efficiency (EE). Reflecting California's longstanding commitment to energy efficiency, there is a strong pre-existing trend of efficiency improvements already present in the time-series data we used to simulate the BAU emissions. Total emissions per unit of GSP declined at an average rate of about 1.8 percent per year from 1990 to 2012. We are therefore concerned that further reductions from our forecast to account for EE improvements would double count the reductions that are already part of the forecast. Indeed, emissions per unit of GSP decline under our BAU forecast by about 1.74 percent per year from 2013 to 2020 . We therefore make no further adjustments in addition to EE effects already integrated into our BAU forecasts.

\section{A.2.1.3 Transportation}

We incorporate the impacts of these complementary policies by calibrating model-year-specific VMT emissions intensities (essentially miles per gallon) and emissions factors for transportation fuel over the period 2013-2020, using EMFAC (2011), ARB's tool for forecasting fleet composition and activity in the transportation sector. ${ }^{16}$ EMFAC estimates VMT and GHG emissions intensity for each on-road vehicle-class by model year and calendar year. Thus, the advantage of explicitly modeling on-road vehicle fleet composition and activity is that we can more precisely simulate the impact of complementary policies that are designed to directly target specific segments of the vehicle fleet.

To account for CAFE, a policy that proposes to drive the average emissions intensity of new light-duty cars and trucks from 26.5 miles per gallon (MPG) in 2011 to 54.5 MPG in 2020, we force the EMFAC forecasts of emissions factors for new light-duty vehicles in model-years 2013-2020 to match the fuel-economy standards established by CAFE. We then calculate fleet-wide annual emissions factors for calendar years 2013-2020, by taking the VMT-weighted sum over the set of all model-year by vehicle-class emissions factors.

We model the implementation of the LCFS as a linear decline in EMFAC's GHG emission factors for on-road gasoline and diesel. ${ }^{17}$ In recognition of the ethanol blend wall, we fix the share of biofuel in gasoline at 11 percent from 2013 through 2020. For diesel, the share of preexisting biofuels is quite small, so we model the penetration of biodiesel as beginning at 2 percent in 2013 and increasing linearly to 10 percent in 2020 .

In order to reflect the underlying random aspects of vehicle emissions, even with successfully implemented complementary policies, we model the effect of these policies by taking random draws from a $\beta(2,2)$ distribution, where the adjusted EMFAC emissions intensity of VMT is the lower bound and the average VMT emissions intensity from our VAR estimates is the upper bound. Abatement is the product of the specific realization of VMT from the VAR and the difference between the specific realization of VMT emissions

\footnotetext{
${ }^{16}$ EMFAC is an engineering-based model that can be used to estimate emissions factors for on-road vehicles operating and projected to be operating in California for calendar years 1990-2035. The model uses historical data on fleet composition, emissions factors, VMT, and turnover to forecast future motor vehicle emissions. Emissions are calculated for forty-two different vehicle classes composed of passenger cars, various types of trucks and buses, motorcycles, and motor homes.

${ }^{17}$ This approach stems from an important difference between the cap-and-trade program and EMFAC methods of accounting for GHG emissions from biofuels. While the cap-and-trade program does not assign a compliance obligation to emissions from ethanol or biodiesel, EMFAC includes combustion emissions from fossil and bio-fuels in its measures of GHG emissions. Therefore, our adjustment of the emissions intensity of gasoline and diesel must take into account not only the incremental contribution of the LCFS, but also the pre-existing levels of biofuels in California transportation fuel.
} 
intensity from the VAR and a random draw from the $\beta(2,2)$ distribution, bounded below by zero. ${ }^{18}$ More formally, realization-specific abatement from transport sector complementary policies can be expressed as:

$$
\text { Abatement }_{m, T+k}=V M T_{m, T+k} \cdot \max \left\{0,\left(E I_{m, T+k}-\beta_{T+k}\right)\right\},
$$

where $V M T_{m, T+k}$ and $E I_{m, T+k}$ are VMT and emissions intensity from simulation draw $\mathrm{m}$ of the VAR during year $T+k$, respectively, and $\beta_{T+k}$ is the transport emissions intensity drawn from the $\beta(2,2)$ distribution in year $T+k$. The row labeled 'Transportation' in the lower panel of Table 4 summarizes the distribution of resulting abatement from these standards as well as from the Low Carbon Fuel Standard.

\section{A.2.1.4 Energy Price Changes Exogenous to Cap-and-Trade}

In addition to the direct effects of regulation, the cost of implementing these complementary policies and other exogenous (to cap-and-trade) factors will likely cause electricity and transportation fuel prices to rise for all customers over the years of our forecast, which will reduce consumption.

To account for the impact of exogenous (to cap-and-trade) drivers on the quantity of electricity demanded we take an average statewide retail electricity price of $\$ 135.3 / \mathrm{MWh}$ in $2012,{ }^{19}$ and assume that this price will increase by 2.15 percent (real) per year. ${ }^{20}$ We incorporate uncertainty by drawing a random elasticity estimate from a $\beta(2,2)$ distribution. For the analysis with complementary policies, we assume an elasticity of -0.1 to -0.2 , which combined with a marginal $\mathrm{CO}_{2}$ e intensity of $0.428 \mathrm{MT} / \mathrm{MWh}$, yields a reduction of 6.4 to $12.8 \mathrm{MMT}$ over the life of the program. For the analysis without complementary policies, we assume a -0.3 to -0.5 elasticity range, which yields the reduction of 19.1 to 31.5 MMT. ${ }^{21}$ The row labeled 'Exogenous Electricity Price Effects' in Table 4 summarizes the distribution of abatement under these assumptions.

Another exogenous driver of higher transportation fuel prices is the LCFS, which could end up significantly raising gasoline prices. Discussions with market participants and regulators suggest that the impact is likely to be capped at $\$ 0.20$ per gallon, and could be much smaller if regulations are relaxed. Reflecting that this price change is the greatest source of uncertainty, we estimate abatement by drawing random a price impact from a $\beta(2,2)$ distribution with a lower bound of $\$ 0.00$ and an upper bound of $\$ 0.20$, applying an elasticity of -0.2 throughout. ${ }^{22}$ The effects of LCFS price impacts are combined with those of the fuel-economy standards and reported in Table 4.

\section{A.2.1.5 Emissions Offsets}

Offsets were expected to be a relatively low-cost (although not free ${ }^{23}$ ) means for a covered entity to meet a portion of its compliance obligation. ${ }^{24}$ As of the start of the program, ARB had approved four categories of

\footnotetext{
${ }^{18}$ We impose a zero lower bound on abatement to account for instances when the specific VAR realization of VMT emissions intensity is below the $\beta(2,2)$ random draw of VMT emissions intensity. Failing to include this lower bound would result in some instances of negative abatement, which seem implausible because the complementary policies are both minimum standards.

${ }^{19}$ See 2012 EIA Electric Power Annual, Table 2.10

${ }^{20}$ This increase is based on a projected real increase for some California utilities from $\$ 144 / \mathrm{MWh}$ in 2012 to $\$ 211 / \mathrm{MWh}$ in 2030, an average increase of 2.15 percent per year. See Energy \& Environmental Economics (2014).

${ }^{21}$ Ito (2014) estimates a medium-long run price elasticity for residential electricity demand of -0.09, suggesting that a lower elasticity might be more relevant under the no complementary policies case when we assume 100 percent pass-through to all types of customers.

${ }^{22}$ While some estimates of the elasticity of demand for transportation fuels are somewhat higher than this, these estimates generally include changes in vehicle choice behavior. Abatement from such changes in fleet composition is already reflected in the auto fuel economy adjustments discussed above.

${ }^{23}$ Most estimates of the price at which offsets would be available put their cost at below or just above the auction reserve price (ARP). We assume that the offsets utilized are available below the ARP. In reality, studies suggest that some may require a price slightly above the ARP, but still likely below $\$ 20 / \mathrm{MT}$. We group these with the abatement available at or slightly above the ARP.

${ }^{24}$ http://www.arb.ca.gov/regact/2010/capandtrade10/capv3appf.pdf.
} 
compliance offset projects that could be used to generate offsets: U.S. Forest Projects; Livestock Projects; Ozone Depleting Substances Projects; and Urban Forest Projects. Additionally, ARB has authorized the use of approximately 5.3 MMT of offsets that were listed under a voluntary early action offset program. However, the total number of offsets expected to be available in the cap-and-trade program is subject to a high degree of uncertainty and best guesses put the estimate substantially below the potential number of offsets that could be used (i.e., 8 percent of compliance obligations). One third-party study from September 2012 estimates the number of offsets available under the four original protocols between 2013 and 2020 at 66 MMT, only 30 percent of the 218 MMT of offsets that theoretically could be used to satisfy compliance obligations. ${ }^{25}$ ARB subsequently added additional offset protocols, such as rice cultivation and mine methane capture and destruction. It was estimated that the addition of these two protocols would more than double the number of offsets available between 2013 and $2020 .{ }^{26}$ To account for the high degree of uncertainty in offset availability, we model offset use as random draw from a $\beta(2,2)$ distribution with a lower bound of 66 MMT and an upper bound of $130 \mathrm{MMT}^{27}$

\section{A.2.1.6 Imported Electricity and Reshuffling}

As discussed in the main text, California's cap-and-trade program attempts to include all emissions from out-of-state fossil-fuel electricity generation delivered to and consumed in the California. However, because it is not possible to physically track the source of electricity supplied to California consumers, importers are instead required to self-report emissions associated with the generation of imported electricity. Electricity importers therefore have an incentive to engage in a variety of practices that lower the reported GHG emissions content of their imports, a class of behaviors broadly labeled reshuffling. While reshuffling would not yield aggregate emissions reductions in the Western Interconnection, it could be a major source of measured emissions reductions under the California cap-and-trade program. ARB has tried to limit reshuffling, focusing on avoiding reshuffling of imports from coal plants partially owned by California utilities.

According to the CEC Energy Almanac, over the last two decades there have been approximately 95 TWh of net electricity imported into California each year, on average. Supposing imported electricity remains at this level through 2020, this implies 760 TWh will be imported from 2013 to 2020. Before the market opened, electric utilities reported to the CEC that they planned to procure $109 \mathrm{TWh}$ of imported electricity under long-term contracts with coal-fired power plants over the 8-year period. To account for ARB's focus on avoiding reshuffling of imports from coal-fired power plants, we hold this quantity fixed at forecasted levels and consider a range of emission intensities for the remaining $651 \mathrm{TWh}$ of imports. We consider a high-intensity case where the remaining imports report an average emissions intensity of 0.284 MT/MWh, two-thirds of the California cap-and-trade market's administratively set default emissions rate applied to any imports that do not claim a specific generation source for the power, and a low-intensity case where the remaining imports report an average emissions intensity of $0.142 \mathrm{MT} / \mathrm{MWh}$, one-third of the default emissions rate. We incorporate uncertainty by drawing a random intensity estimate from a $\beta(2,2)$ distribution bounded by our high- and low-intensity cases.

To calculate emissions reductions from imports we multiply $651 \mathrm{TWh}$ - the quantity of imports net of coal - by the difference between $0.326 \mathrm{MT} / \mathrm{MWh}$ - the emissions intensity implied by our BAU estimate of emissions from imports - and a random draw from our $\beta(2,2)$ distribution. $^{28}$ More formally, realization-

\footnotetext{
${ }^{25}$ http://americancarbonregistry.org/acr-compliance-offset-supply-forecast-for-the-ca-cap-and-trade-program.

${ }^{26}$ Ibid.

${ }^{27}$ We assume a single 8-year compliance time horizon. As a result, the analysis does not address the fact that current rules do not allow a shortfall of offsets in an earlier compliance periods to be recaptured in later time periods, and thus results in a permanent shortfall in offsets from the theoretical potential. It seems quite likely that this rule would be adjusted if the allowance price increased and the limit on offsets were constraining.

${ }^{28}$ Our BAU assumes annual emissions from imported electricity will be 40.17 MMT. Subtracting 13.63 MMT for specified imports from coal-fired plants, and supposing $81.37 \mathrm{TWh}$ of annual imports from other sources (i.e., total net imports less
} 
Table A.14: Electricity Import Emissions Calculation

\begin{tabular}{|l|c|c|c|c|c|c|}
\hline & \multicolumn{3}{|c|}{ Electricity Import Emissions } & \multicolumn{2}{c|}{ Abatement from Baseline } \\
\hline Year & $\begin{array}{c}\text { Baseline } \\
\text { MMT }\end{array}$ & $\begin{array}{c}\text { Coal } \\
\text { MMT }\end{array}$ & $\begin{array}{c}\text { Non-Coal (low) } \\
\text { MMT }\end{array}$ & $\begin{array}{c}\text { Non-Coal (high) } \\
\text { MMT }\end{array}$ & $\begin{array}{c}\text { Low } \\
\text { Forecast }\end{array}$ & $\begin{array}{c}\text { High } \\
\text { Forecast }\end{array}$ \\
\hline \hline 2013 & 40.17 & 18.42 & 11.14 & 22.29 & 10.61 & 0.00 \\
2014 & 40.17 & 18.20 & 11.17 & 22.34 & 10.80 & 0.00 \\
2015 & 40.17 & 14.62 & 11.64 & 23.28 & 13.91 & 2.27 \\
2016 & 40.17 & 14.62 & 11.64 & 23.28 & 13.91 & 2.27 \\
2017 & 40.17 & 14.62 & 11.64 & 23.28 & 13.91 & 2.27 \\
2018 & 40.17 & 12.96 & 11.86 & 23.71 & 15.35 & 3.49 \\
2019 & 40.17 & 12.96 & 11.86 & 23.71 & 15.35 & 3.49 \\
2020 & 40.17 & 12.96 & 11.86 & 23.71 & 15.35 & 3.49 \\
\hline Total & 321.36 & 119.37 & 92.80 & 185.61 & 109.19 & 16.38 \\
\hline
\end{tabular}

specific abatement from reshuffling can be expressed as:

$$
\text { Abatement }_{m, T+k}=81.37 \cdot\left(0.326-\beta_{m}\right) .
$$

To summarize the results of this calculation, we consider reductions from an 8-year BAU of 321 MMT. Under the high-emissions scenario, emissions from electricity imports would be 305, producing an 8-year reduction of 16 . Under the low-emissions scenario, emissions would be 212, yielding an 8-year reduction of 109 MMT. Annual emissions from electricity imports under these assumptions are summarized in Table A.14.

\section{A.2.2 Price-Responsive Abatement}

In order to assess the impact of the change in the allowance price on the quantity demanded in the allowance market, we first analyze price-elastic demand for emissions allowances in four areas on the consumer side: demand for gasoline, diesel, electricity, and natural gas. For each of these areas, we calculate the emissions reduction that would occur with the price at the ARP, at the price to access the lowest tier of the allowance price containment reserve (APCR), and at the price to access the highest tier of the APCR. ${ }^{29}$ We also consider responses of industrial emissions to allowance prices.

For this analysis, we assume full pass-through of the GHG allowance price to end-use consumers. To the extent that some pass-through is reduced through other policies, this will overstate the degree of priceresponse of GHG emissions abatement. We recognize that output-based free allocation of allowances to some trade exposed industries will dampen the effect of allowance prices on the final product prices, but even in these industries, process improvements to lower GHG emissions will still be incentivized by the full price of the allowance. ${ }^{30}$

specified coal) the average emission factor for non-coal-fired imports would be $0.326 \mathrm{MT} / \mathrm{MWh}$ (about 23 percent below the default emissions factor).

${ }^{29}$ Each of these price levels escalates over time in real terms, so we calculate the price-responsive abatement for each year separately.

${ }^{30}$ For transportation fuels, we assume full pass-through of the GHG emissions cost of tailpipe emissions, but no pass-through of GHG cost from refinery emissions to final fuel prices due to output-based free allocation. 


\section{A.2.2.1 Allowance Price Trajectory}

The price of allowances at any point in time will reflect a weighted average of the probabilities of different equilibrium outcomes. So, price will evolve over time as new information becomes available, eventually ending at the aggregated equilibrium price. A full dynamic model of this process would be a large and complex undertaking, which we do not attempt here. Instead, for each of the 1000 random draws, we assume a linear price path from the start of the program to the end of $2020 .^{31}$ The trajectories are illustrated in Figure A.2.

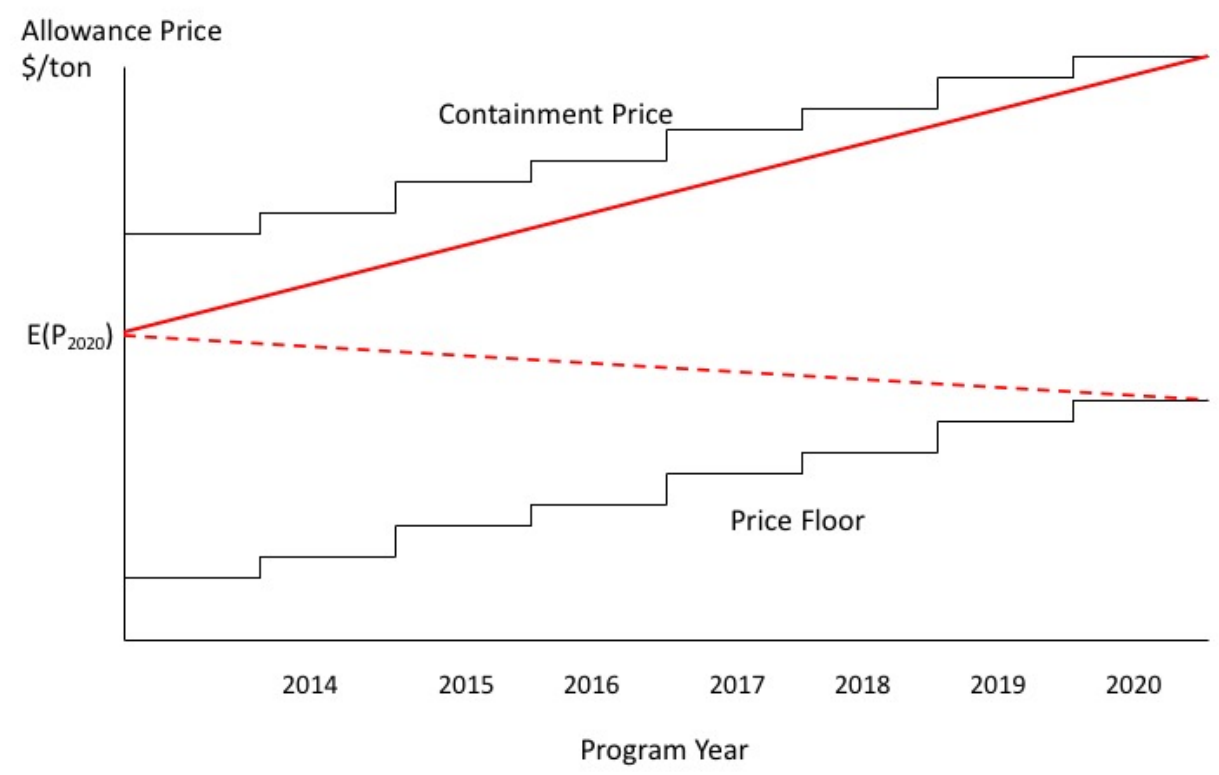

Figure A.2: Assumed Trajectories of Allowance Prices Conditional on Endpoints

The details of this approximation are as follows: We begin by creating a probability distribution of the aggregate market equilibrium under the assumption that for each draw the GHG price to which demand will respond in every year is the 2020 equilibrium price associated with that draw, discounted back to each year at a 5 percent real discount rate. From this price distribution we create a price for 2013 that is the probabilityweighted average of the (discounted) 2020 possible price outcomes. For each draw, we then assume that the price to which demand responds follows a linear path from this 2013 price to whatever equilibrium price results from that draw. This creates a new distribution of probabilities for prices in 2020, which in turn creates a new discounted price in 2013 that reflects the probability-weighted average of 2020 outcomes. We then recalculate the linear price paths for each draw. This iterative process converges quickly so that the price-responsive abatements in response to these price paths create a distribution of 2020 equilibrium prices that, after discounting, is within $\$ 0.01$ of the 2013 price that we assume begins the linear price path. This implies that all price paths to 2020 begin at the same 2013 level, with some increasing to the highest tier of

\footnotetext{
${ }^{31}$ And similarly for the analysis of the program extension to 2030, we assume a linear price path from 2018 to 2030 . We start in 2018, because the extension legislation was not passed until July 2017 and the implementation rules for the extension were still uncertain as of late 2017 .
} 
the APCR, ${ }^{32}$ others decreasing to the price floor, and others ending at some price in between the floor and highest APCR tier. Assuming that the price follows such a linear path has a small effect on the mean level of price-responsive abatement, but substantially reduces the variance of price-responsive abatement compared to assuming that the price in every year is the (discounted) final year price.

\section{A.2.2.2 Demand for Fuels}

The potential impact of the allowance price on the consumption of transportation fuels - gasoline and diesel - is a function of short-run effects, such as driving less and switching among vehicles a family or company owns, ${ }^{33}$ and longer-run effects, such as buying more fuel-efficient vehicles and living in areas that require less use of vehicles. If, however, fuel-economy standards have pushed up the average fuel-economy of vehicles above the level consumers would otherwise voluntarily choose given fuel prices, then raising fuel prices will have a smaller effect, because the fuel-economy regulation has already moved some customers into vehicles with a fuel economy as great or greater than they would have chosen in response to higher gas prices. For this reason, in jurisdictions with binding fuel-economy standards, such as California, the price-elasticity of demand for transportation fuels is likely to be smaller. Similarly, if urban planning policies are undertaken to reduce auto usage independent of the allowance price, then price-responsive changes to transportation demand will be muted. Short-run estimates of the price elasticity are generally -0.2 or smaller. ${ }^{34}$ Long-run elasticities are generally between -0.3 and $-0.5 .{ }^{35}$ Furthermore, the fuel-economy standards would reduce the absolute magnitude of emissions reductions in another way: by lowering the base level of emissions per mile even before the price of allowances has an effect. Recall that we incorporate the direct impact of fuel-economy standards on emissions, holding constant vehicle miles traveled, when we account for transport emissions intensities in the VAR simulation. ${ }^{36}$

We recognize that improved fuel-economy standards will phase in gradually during the cap-and-trade compliance periods. To balance these factors, we assume that the base level of vehicle emissions is unchanged from 2012 levels in calculating the price response, and we assume that the price elasticity of demand will range from - 0.1 to -0.2 . We assume 100 percent pass-through of allowance prices on tailpipe emissions to the cost of gasoline. Many studies on pass-through of fuel taxes and crude oil price changes, including Borenstein, Cameron and Gilbert (1997), Lewis (2011), and Marion and Muehlegger (2011), have found pass-through to retail price equal or very close to 100 percent.

Using an allowance price trajectory, as described above, reaching the highest price in the price containment reserve in 2020 which (in 2015 real dollars) is $\$ 72.12,{ }^{37}$ and assuming a -0.1 price elasticity of demand, yields a reduction of 6.4 MMT over the life of the program from reduced use of gasoline. For diesel, the same allowance price trajectory, ${ }^{38}$ yields a reduction of $1.8 \mathrm{MMT}$ over the life of the program.

Assuming an elasticity of -0.2 about doubles the reduction from transportation fuels to 16.3 MMT. As part of the later analysis without complementary policies, we also consider the potentially more-elastic response if vehicle fuel economy standards are not separately increased. Assuming elasticities of $-0.3,-0.4$, and -0.5 yields reductions of 24.3 MMT, 32.2 MMT, and 40.1 MMT, respectively. Note that transportation fuels are under the cap only in 2015-2020, so we calculate reductions for only these six years. When we examine the market with no complementary policies, we combine the -0.3 to -0.5 elasticity range with the

\footnotetext{
${ }^{32}$ Even though there was no firm price ceiling at the time the market was launched, we assume that market participants believed the price would not be allowed to go higher than the highest step of the APCR.

${ }^{33}$ See, for instance, Archsmith et. al. (2017).

${ }^{34}$ See Hughes, Knittel and Sperling (2008). Levin, Lewis and Wolak (2017) suggests that medium run elasticities are more likely to be in the range of -0.3 .

${ }^{35}$ See Dahl (2012)

${ }^{36}$ The VAR also accounts for estimates of uncertainty in the change in gasoline prices absent GHG costs.

${ }^{37}$ This translates to an increase of about $\$ 0.57$ per gallon of gasoline at the pump in 2015 dollars (after accounting for 10 percent biofuels).

${ }^{38}$ This trajectory translates to an increase of about $\$ 0.73$ per gallon of diesel at the pump in 2015 dollars.
} 
BAU transport emissions intensity described in the previous section, essentially assuming this higher price elasticity if higher fuel-economy standards had not been effectively implemented.

In the primary scenario with complementary policies, we also consider the potential impact of the LCFS on gasoline prices and gasoline quantity consumed, as discussed above.

\section{A.2.2.3 Demand for Electricity}

In California, the impact of a rising allowance price on emissions from electricity consumption depends primarily on the pass-through of allowance costs to retail prices of electricity, because a rising GHG price has relatively little impact of the ordering of marginal production costs among in-state fossil fuel generation. ${ }^{39}$ The three large regulated investor-owned utilities (IOUs) that serve about 85 percent of load in California receive free allocations of allowances that they must then sell in the allowance auctions, resulting in revenues to the utilities. Those revenues must then be distributed to customers. They could be used to reduce the retail rate increases that would otherwise occur due to higher wholesale electricity purchase prices caused by generators' allowance obligations for their GHG emissions, but some share were to be distributed to residential customers lump sum. Publicly-owned utilities that serve the remainder of demand were not obligated to sell their allowances, and were free to decide how much of the value of the free allowances to use to offset retail rate increases that would result from higher wholesale electricity prices.

Based on a resolution from the CPUC in December 2012, ${ }^{40}$ a best guess at the outset of the program seemed to be that the revenues from utility sales of allowances would be used first to assure that the cap-and-trade program causes no price increase to residential consumers. In addition, the revenues would be allocated to dampen price increases for small commercial customers and likely greatly reduce them for energy-intensive trade-exposed large industrial and commercial customers. Remaining revenues would be distributed to residential customers through a semi-annual lump-sum per-customer credit.

It appears that most electricity sold to commercial and industrial customers would see more than 100 percent pass-through of energy price increases due to allowance costs. ${ }^{41}$ Borenstein et al (2016) discusses the possible interpretations of the CPUC decision and how it would allocate a disproportionate share of the wholesale cost increase from cap-and-trade to industrial and commercial customers and protect residential customers from rate increases. For the purpose of our analysis, however, imposing a more-than-100 percent pass-through on a subset of customers to cover the remaining (residential) customers who see no increase has nearly the same effect on total consumption as assuming 100 percent pass-through to all customers. ${ }^{42}$ So, for simplicity, we simply assume 100 percent pass-through of increased electricity costs to all retail customers.

With a statewide average GHG intensity of 0.326 metric tonnes (MT) per MWh (based on the 2012 GHG inventory), this means that the cost of electricity generation per MWh would increase by 0.326 times the allowance price. At an allowance price of $\$ 50 / \mathrm{MT}$, this raises average rates by $\$ 16.30 / \mathrm{MWh}$ and at $\$ 70.36 / \mathrm{MT}$ by $\$ 22.94 / \mathrm{MWh}^{43}$ We apply these increases to the state average retail rates of all customer

\footnotetext{
${ }^{39}$ Bushnell, Chen, and Zaragoza-Watkins (2014).

${ }^{40}$ http://docs.cpuc.ca.gov/PublishedDocs/Published/G000/M040/K841/40841421.PDF. The full decision is at http://docs.cpuc.ca.gov/PublishedDocs/Published/G000/M039/K594/39594673.PDF.

${ }^{41}$ It is worth noting that it is far from straightforward once the program begins for a regulator to know what the counterfactual price of electricity would have been if allowances had sold for a different price or for a price of zero. The price of allowances has a complex impact of wholesale electricity expenditures depending on the emissions intensity of the marginal supplier versus the average supplier and the competitiveness of the wholesale electricity market. Thus, it is not clear how the CPUC would make good on a promise not to pass-through the cost of allowances without a detailed study of the impact that cost on equilibrium wholesale electricity prices.

${ }^{42}$ This would not be the case if residential customer demand were clearly more or less elastic than demand from commercial and industrial customers. There is not, however, consistent evidence in either direction.

${ }^{43}$ The $0.326 \mathrm{MT} / \mathrm{MWh}$ figure is arrived at by taking total 2012 GHG electricity emissions measured for in-state (44.9 MMT) and for imports (39.8 MMT) and dividing by total consumption (259.5 MMWh). This assumes that the wholesale price obligation is increased by the cost of the allowances, when it could be more or less depending on the GHG intensity of the marginal versus the average producer and the share of long-term supply contracts with prices set prior to or independent of the
} 
classes, based on EIA data, to get a weighted average percentage price response.

The choice of an elasticity for incorporating price-responsive changes in electricity usage due to the carbon price again confronts the issue of short-run versus long-run decision-making by customers. As with transportation fuels, other regulations that improve energy efficiency - such as building codes and regulation of appliance efficiency - are likely to lower the demand response to increased electricity prices. There have been many studies of residential electricity demand, which suggest a short-run elasticity below -0.2 and a long-run elasticity mostly in the range of -0.3 to $-0.5 .{ }^{44}$ Commercial and industrial electricity demand elasticity estimates are few in number and not at all consistent. Kamerschen and Porter (2004) estimates a long-run industrial price elasticity of demand of -0.35 when controlling for heating and cooling degreedays. Based on these estimates, we use a range of -0.1 to -0.2 for the price elasticity of demand in the presence of complementary policies, and -0.3 to -0.5 for longer run elasticity, assuming no damping effect of complementary policies.

Because the resulting impact on electricity consumption would be a reduction at the margin, we multiply the demand reduction by an assumed marginal GHG intensity - which we take to be $0.428 \mathrm{MT} / \mathrm{MWh}$ - to calculate the reduction in emissions at different prices. ${ }^{45}$ The result is a reduction of 7.7 MMT when the price equilibrates at the auction reserve by the end of the program, 26.9 MMT when price ends at the lowest step of the APCR, and 32.9 MMT when price is at the highest step of the APCR in $2020 .{ }^{46}$

\section{A.2.2.4 Demand for Natural Gas}

In 2012, it appeared that ARB policy would give free allowances to natural gas distribution companies (which are nearly all investor-owned regulated utilities in California) equal to their obligation associated with their 2011 supply to non-covered entities (less than 25,000 $\mathrm{MT}$ of $\mathrm{CO}_{2} \mathrm{e}$ per year), but then declining at the cap decline factor. The utilities receiving the free allowances would then consign them to the quarterly auctions and receive revenues. The utility would then be responsible for procuring allowances equal to the GHG emissions associated with all its sales of natural gas including to the non-covered entities. Importantly, however, the CPUC had decided that the revenues from the free allowances should be returned to customers on a non-volumetric basis. ${ }^{47}$ As a result, the marginal cost of procuring and selling natural gas would rise by the associated allowance cost for GHGs. ${ }^{48}$ Thus, we assume 100 percent pass-through of GHG allowance costs to the volumetric natural gas prices of utilities.

Large industrial natural gas consumers were not as a class allocated free allowances either directly if they procured their own gas or indirectly to the utility if they purchased through the utility. As discussed in the text, some industrial customers were allocated free allowances through output-based allocation in order to reduce leakage. This effectively lowered their marginal cost of producing their output, and reduced the pass-through of GHG costs to their final goods customers. However, these customers still had an incentive to reduce natural gas consumption in their production processes. For simplicity, we assume that the outputbased allocation did not materially reduce the price responsiveness of demand for allowances from large industrial natural gas customers.

\footnotetext{
impact of GHG costs on the market price.

${ }^{44}$ See Ito (2014) and Fell et al (2014) for two recent estimates and references to the earlier literature.

${ }^{45} 0.428 \mathrm{MT} / \mathrm{MWh}$ is the default rate assigned to "unspecified" source of electricity under the cap-and-trade program. The marginal GHG intensity of 0.428 is based roughly on the efficiency of a combined-cycle gas turbine generator. If some of the reduction comes out of renewable, hydro, or nuclear generation the marginal intensity will be lower. The impact scales linearly with the assumed marginal GHG intensity.

${ }^{46}$ The baseline price from which all price increases are calculated is the average price of electricity, assumed constant in real terms over 2013-2020.

${ }^{47}$ Since this time, there have been lengthy legal proceedings at the CPUC and protests about the non-volumetric basis for refunds, but that opinion has prevailed thus far.

${ }^{48}$ For a history of this policy discussion, see http://docs.cpuc.ca.gov/PublishedDocs/Efile/G000/M197/K205/197205891.PDF.
} 
As explained in the text, in the first compliance period (2013-2014), only large industrial customers incurred a compliance obligation from natural gas combustion (whether they purchased the gas directly or through the gas utility). These customers comprised approximately 59 percent of gas demand, so as discussed above, we calculate abatement in those years assuming only 59 percent is covered. During 2015-2020, all gas consumption was to be covered by the program, and we calculate the price response of abatement accordingly.

If the cost of natural gas emissions were fully passed through to customers, then it would raise the price of natural gas by $\$ 0.0543$ per MMBTU for every dollar per tonne of allowance price. Based on Auffhammer and Rubin (2018) and Bernstein and Griffin (2006), we assume a demand elasticity of -0.1 to -0.3 for analysis of price-responsive abatement in the presence of complementary policies, slightly higher than most of the short-run elasticity estimates. It is worth noting that much of the natural gas combustion (other than for electricity generation) is used for heating buildings and water and California's Title 24 imposes the most aggressive energy efficiency standards in the country for building design, insulation and other energy use. ${ }^{49}$ California also has many programs to subsidize energy efficiency upgrades for both residential and commercial/industrial customers. For the absence of complementary policies (section V.A) - including building standards - we assume a demand elasticity range of -0.3 to -0.5 , reflecting longer-run elasticity estimates. ${ }^{50}$ We then draw realized elasticities from a $\beta(2,2)$ distribution with this support.

For the first compliance period, when only industrial customers are covered, we use the baseline retail price of \$5.77, EIA's reported average price of natural gas for industrial customers in 2012, and the 2012 industrial consumption for the baseline quantity. For later years, we use the volume-weighted average retail price across industrial, commercial, and residential customers and the total consumption from these three sectors. ${ }^{51}$

\section{A.2.2.5 Abatement from Out-of-State Electricity Dispatch Changes}

To the extent that some high-emitting out-of-state coal plants are not reshuffled or declared at the emissions default rate, there is possible elasticity from higher allowance prices incenting reduced generation from such plants. We considered this, but current ARB policy suggests that short-term energy trades would fall under a safe harbor and would not be considered reshuffling. If that is the case, then an operator would be better off carrying out such trades than actually reducing output from the plant. This suggests that allowance price increases might incent some changes in reported emissions. In any case, we consider that as part of the analysis of price non-responsive abatement discussed above.

\section{A.2.2.6 Industrial Emissions}

For the industries covered under output-based updating, there may still be some emissions reductions as the allowance price rises. This could happen in two ways. First, once a baseline ratio of allowances to output is established, these firms have an incentive to make process improvements that reduce GHG emissions for a given quantity of output. It is unclear how much of such improvement is likely to occur. At this point we have no information on this. Our current estimates assume this is zero. ARB's analysis of compliance pathways suggests that at a price of up to $\$ 18 /$ tonne (25 percent of the highest price of the APCR in 2020), the opportunity for industrial process reduction is at most 1-2 MMT per year. ${ }^{52}$ Second, because the outputbased updating is not 100 percent, additional emissions that result from marginal output increases do impose some marginal cost on the firms. That impact is likely to be small, however, because the effective updating

\footnotetext{
${ }^{49}$ See, for instance, http://www.energy.ca.gov/title24/2008standards/residential_manual.html .

${ }^{50} \mathrm{As}$ with the previous energy demands, there are estimates of higher elasticities in the literature, but they generally include switching to other fossil fuel energy sources.

${ }^{51}$ See EIA Natural Gas Annual, 2012.

${ }^{52}$ See figures F-3 through F-9 of Appendix F, "Compliance Pathways Analysis," available at http://www.arb.ca.gov/regact/2010/capandtrade10/capv3appf.pdf.
} 
Table A.15: Summary of Potential for Price-Responsive Emissions Abatement

\begin{tabular}{|c|c|c|c|c|c|c|}
\hline & \multicolumn{6}{|c|}{ Scenarios with Complementary Policies } \\
\hline $\begin{array}{l}\text { Price-responsive } \\
\text { Allowance Demand } \\
\text { Reduction }\end{array}$ & \multicolumn{2}{|c|}{ Elasticities } & \multicolumn{2}{|c|}{$\begin{array}{l}\text { Range of Energy Price Changes } \\
\text { At Different Levels of Allowance } \\
\qquad 2013-2030(\$ 2015) \text { : }\end{array}$} & \multicolumn{2}{|c|}{$\begin{array}{c}\text { Abatement in program } \\
\text { at APCR (MM tons) } \\
\text { cumulative } 2013 ; 2015-2030\end{array}$} \\
\hline Sector & Low & High & $\begin{array}{l}\text { Auction } \\
\text { Reserve }\end{array}$ & APCR & Low Elas & High Elas \\
\hline $\begin{array}{l}\text { Electricity }(\$ / \mathrm{MWh}) \\
\text { Transportation }(\$ / \text { Gallon) } \\
\text { Natural Gas }(\$ / \text { MBTU) }\end{array}$ & $\begin{array}{l}-0.1 \\
-0.1 \\
-0.1\end{array}$ & $\begin{array}{l}-0.2 \\
-0.2 \\
-0.3\end{array}$ & $\begin{array}{l}\$ 3.58 / \$ 5.04 \\
\$ 0.10 / \$ 0.13 \\
\$ 0.60 / \$ 0.84\end{array}$ & $\begin{array}{l}\$ 16.73 / \$ 23.54 \\
\$ 0.47 / \$ 0.60 \\
\$ 2.78 / \$ 3.92\end{array}$ & $\begin{array}{c}6.51 \\
8.20 \\
16.11\end{array}$ & $\begin{array}{l}12.94 \\
16.32 \\
46.76\end{array}$ \\
\hline $\begin{array}{l}\text { Price-responsive } \\
\text { Allowance Demand } \\
\text { Reduction }\end{array}$ & \multicolumn{2}{|c|}{ Elasticities } & \multicolumn{2}{|c|}{$\begin{array}{l}\text { Range of Energy Price Changes } \\
\text { At Different Levels of Allowance } \\
\qquad 2013-2030(\$ 2015) \text { : }\end{array}$} & \multicolumn{2}{|c|}{$\begin{array}{c}\text { Abatement in program } \\
\text { at APCR (MM tons) } \\
\text { cumulative } 2013 ; 2015-2030\end{array}$} \\
\hline Sector & Low & High & $\begin{array}{l}\text { Auction } \\
\text { Reserve }\end{array}$ & APCR & Low Elas & High Elas \\
\hline $\begin{array}{l}\text { Electricity }(\$ / \mathrm{MWh}) \\
\text { Transportation }(\$ / \text { Gallon) } \\
\text { Natural Gas }(\$ / \text { MBTU) }\end{array}$ & $\begin{array}{l}-0.3 \\
-0.3 \\
-0.3\end{array}$ & $\begin{array}{l}-0.5 \\
-0.5 \\
-0.5\end{array}$ & $\begin{array}{l}\$ 3.58 / \$ 5.04 \\
\$ 0.10 / \$ 0.13 \\
\$ 0.60 / \$ 0.84\end{array}$ & $\begin{array}{l}\$ 16.73 / \$ 23.54 \\
\$ 0.47 / \$ 0.60 \\
\$ 2.78 / \$ 3.92\end{array}$ & $\begin{array}{l}19.95 \\
24.84 \\
47.92\end{array}$ & $\begin{array}{l}32.87 \\
40.96 \\
77.29\end{array}$ \\
\hline
\end{tabular}

Notes: All energy price changes assume $100 \%$ pass-through.

Range of price changes shown are for first and last year covered by cap and trade program.

Range of price changes for Transportation and are for 2015-2020 only

Range of price changes for Electricity and large users of Nat. Gas for 2013-2020

Range of Transportation price changes based on weighted average of gasoline and diesel

Transportation abatement is for tailpipe emissions only, does not include associated upstream emissions

factors average between 75 percent and 90 percent over the program, which implies that the firm faces an effective allowance price of 10 percent to 25 percent of the market price for emissions that are associated with changes in output. At this point, we have not incorporated estimates of this impact, but it seems likely to be quite small.

\section{A.2.2.7 Summary of Potential for Price-Responsive Abatement}

Table A.15 summarizes the potential impact of allowance prices on energy prices and the potential resulting price-responsive abatement along different trajectories, to the ARP and to the highest tier of the APCR. Even with the much higher elasticities that we assume when there are no complementary policies, the aggregate abatement is likely to be small compared to the uncertainty in BAU emissions and other exogenous sources of abatement.

\section{A.3 Alternative Allowance Price Results}

In the text and in section A.1 we describe alternative approaches to modeling BAU emissions and supply of abatement. In this section we summarize results for these alternative approaches. 


\section{A.3.1 No Complementary Policies}

In section III of the main text we summarize how we adjust for several complementary policies that provide a horizontal shift to the abatement supply curve. These complementary policies also impact the elasticity of response to allowance prices, rotating the slope of the abatement supply curve, as discussed in subsection V.A of the main text. When we remove the fuel economy regulations, we assume this increases the price elasticity of gasoline demand and consequently the elasticity of transportation emissions to the price of allowances. The logic of this assumption is that customers would choose to purchase more fuel-efficient vehicles under high gasoline and allowance price outcomes, whereas under the fuel economy standards they would be required to purchase fuel efficient vehicles under any scenario. Therefore, we increase the elasticity of demand for diesel and gasoline from a range of -0.1 to -0.2 to a range from -0.3 to -0.5 . Similarly, we assume that the removal of energy efficiency programs and other customer-facing complementary policies increase the elasticity of demand for natural gas and electricity also increase to -0.3 to -0.5 .

Figure A.3 presents the equivalent of Figure 4 from the text under the assumptions of adopted in the section V.A with no complementary policies. For comparison, Figure A.4 reprints Figure 4 from the text. Abatement supply is more price elastic under this set of assumptions and the upward sloping portion of the abatement supply curve - above the ARP, but below the steps of the APCR - now falls in a higherprobability region of the BAU probability density function. Still, as reported in the text, the probability of the equilibrium outcome falling in this range is only 6.2 percent.

\section{A.3.2 Alternative BAU Estimates}

In subsection A.1.6 we described three alternative approaches for estimating the distribution of future BAU emissions. In this subsection we present potential implications of those approaches for the distribution of market equilibria.

In order to get to the market equilibria, however, one needs estimates of the distribution of abatement supply. Recall that for our primary analysis, estimates of the abatement supply from complementary policies came in part from the estimation of the seven-variable VAR. In particular, estimates of the GHG reduction from transportation and in-state thermal electricity generation were derived from the estimated paths of VMT and GHG intensity of transportation in one case, and in-state thermal electricity generation and the GHG intensity of that generation in the other case. It is not straightforward to derive similar estimates from the two-sample error correction model, because of the separate estimation for the two samples, and the bivariate vector autoregression and sampling from past growth rates with replacement do not yield any estimates of abatement supply. For this reason, and to present a comparison that is not driven by different abatement supply estimates, we present results for all four approaches using the abatement supply from our primary analysis. The difference in the outcomes is driven entirely by differences in estimates of BAU emissions.

Figure A.5 presents our primary results alongside the results from the three alternative approaches. The upper left graph replicates our primary results from Figure 4 from the text. The other three graphs show the equivalent presentation of results from the three alternative approaches. In all cases, the probability of an interior solution is quite small. In our primary results, it was estimated to be 1.1 percent. Using the two-sample error correction model, it is estimated to be 2.2 percent, while the estimates are 4 percent with the cointegrated bivariate vector autoregression, and less than 1 percent using the simplest model of just sampling growth rates (with replacement) from the 20 years of GHG data. 
Appendix References

Archsmith, James, Kenneth Gillingham, Christopher R. Knittel and David S. Rapson. "Attribute Substitution in Household Vehicle Portfolios." National Bureau of Economic Research Working Paper \#23856, September 2017.

Auffhammer, Maximilian and Edward Rubin. "Natural Gas Price Elasticities and Optimal Cost Recovery Under Consumer Heterogeneity: Evidence from 300 Million Natural Gas Bills." Energy Institute at Haas Working Paper \#287, January 2018.

Available at https://ei.haas.berkeley.edu/research/papers/WP287.pdf.

Bernstein, Mark A., and James Griffin. "Regional differences in the price-elasticity of demand for energy." No. NREL/SR-620-39512. National Renewable Energy Laboratory (NREL), Golden, CO., 2006.

Borenstein, Severin, Colin Cameron, and Richard Gilbert. "Do Gasoline Prices Respond Asymmetrically to Crude Oil Price Changes?" Quarterly Journal of Economics 112(February 1997).

Borenstein, Severin, James Bushnell, Frank A. Wolak, and Matthew Zaragoza-Watkins. "Expecting the Unexpected: Emissions Uncertainty and Environmental Market Design.” No. w20999. National Bureau of Economic Research, (August 2016).

Bushnell, James, Yihsu Chen, and Matthew Zaragoza-Watkins. "Downstream regulation of $\mathrm{CO}_{2}$ emissions in California's electricity sector." Energy Policy 64, (2014): 313-323.

Box, George EP, and David A. Pierce. "Distribution of residual autocorrelations in autoregressive-integrated moving average time series models." Journal of the American Statistical Association 65 (332), (1970): 1509-1526.

California Air Resources Board, "Greenhouse Gas Emissions Inventory Technical Support Document." (2010).

California Air Resources Board, "Regulation for the Mandatory Reporting of Greenhouse Gas Emissions." (2011).

California Air Resources Board, "Board Resolution 12-51." (2012).

California Air Resources Board, "California Cap on Greenhouse Gas Emissions and Market Based Compliance Mechanisms." (2013).

California Air Resources Board, "Initial Statement of Reasons: Amendments to the California Cap on Greenhouse Gas Emissions and Market Based Compliance Mechanisms." (2013).

California Energy Commission, "California Installed Capacity and Generation." (2012).

California Energy Commission, "Energy Consumption Database." (2013).

California Public Utilities Commission, "Renewable Portfolio Standard Calculator for the Transmission Planning Process." (2013).

California Public Utilities Commission, "Decision Adopting a cap-and-trade Greenhouse Gas Allowance Revenue Allocation Methodology for the Investor-Owned Electric Utilities." (2012).

Dahl, Carol A., " Measuring global gasoline and diesel price and income elasticities." Energy Policy 41, (2012): 2-13.

Davidson, Russell, and Emmanuel Flachaire. "The wild bootstrap, tamed at last." Journal of Econometrics. 146, no. 1 (2008): 162-169.

Dickey, David A., and Wayne A. Fuller. "Distribution of the estimators for autoregressive time series with a unit root." Journal of the American Statistical Association 74(366a), (1979): 427-431.

Diebold, Francis X., and Lutz Kilian. "Unit-root tests are useful for selecting forecasting models." Journal of Business \&3 Economic Statistics 18, no. 3 (2000): 265-273.

Efron, Bradley, and Robert Tibshirani. An introduction to the bootstrap. Vol. 57. CRC press, 1993.

Elliot, B. E., T. J. Rothenberg, and J. H. Stock. "Efficient tests of the unit root hypothesis." Econometrica 64(8), (1996): 13-36. 
Energy \& Environmental Economics. Investigating a Higher Renewables Portfolio Standard in California, January 2014.

Engle, Robert F., and Granger, Clive W., "Co-integration error correction: Representation, estimation and testing." Econometrica 55(2), (1987): 251-276.

Engle, Robert F., and Byung Sam Yoo. "Forecasting and testing in co-integrated systems." Journal of Econometrics 35(1), (1987): 143-159.

Fell, Harrison, Dallas Burtraw, Richard Morgenstern, and Karen Palmer. "Climate Policy Design with Correlated Uncertainties in Offset Supply and Abatement Cost." Land Economics 88(3), (2012).

Hobbs, Benjamin F., James Bushnell, and Frank A. Wolak. "Upstream vs. downstream $\mathrm{CO}_{2}$ trading: A comparison for the electricity context." Energy Policy 38(7), (2010): 3632-3643.

Hosking, John RM. "The multivariate portmanteau statistic." Journal of the American Statistical Association 75(371), (1980): 602-608.

Hughes, Jonathan E., Christopher R. Knittel and Daniel Sperling, "Evidence of a shift in the short-run price elasticity of gasoline." The Energy Journal, 29(1), (2008): 113-34.

Ito, Koichiro. "Do consumers respond to marginal or average price? Evidence from nonlinear electricity pricing." American Economic Review, 104(2), (2014): 537-63.

Johansen, Søren. "Statistical analysis of cointegration vectors." Journal of Economic Dynamics and Control, 12, (1988): 231-254

Johansen, Søren. Likelihood-based inference in cointegrated vector autoregressive models. New York: Oxford University Press, (1995).

Johansen, Søren. "Interpretation of cointegrating coefficients in the cointegrated vector autoregressive model." Oxford Bulletin of Economics and Statistics 67(1), (2005): 93-104.

Kamerschen, David R., and David V. Porter. "The demand for residential, industrial and total electricity, 1973-1998." Energy Economics, 26(1), (2004): 87-100.

Levin, Laurence, Matthew S. Lewis, and Frank A. Wolak. "High Frequency Evidence on the Demand for Gasoline." American Economic Journal: Economic Policy, 9(3), (2017): 314-47.

Lewis, Matthew S. "Asymmetric Price Adjustment and Consumer Search: An Examination of the Retail Gasoline Market." Journal of Economics and Management Strategy, 20 (2), (Summer 2011): 409-449.

Lutkepohl, Helmut. "Interpretation of cointegration relations." Econometric Reviews 13(3), (1994): 391-394.

Marion, Justin and Erich Muehlegger. "Tax Incidence and Supply Conditions." Journal of Public Economics, 95(9-10) (2011): 1202-1212.

U.S. Bureau of Economic Analysis, "Real Gross Domestic Product by State." (2012).

U.S. Energy Information Administration, Natural Gas Annual, 2012. Available at https://www.eia.gov/naturalgas/annual/pdf/nga12.pdf.

U.S. Energy Information Administration, Electric Power Annual, 2012 Available at https://www.eia.gov/electricity/annual/backissues.php.

U.S. Energy Information Administration, "California Average Retail Price of Electricity to Ultimate Customers by End-Use Sector." (2013).

U.S. Energy Information Administration, "California Natural Gas Prices." (2013).

U.S. Energy Information Administration, "California Weekly Retail Gasoline and Diesel Prices." (2012).

U.S. Environmental Protection Agency. "U.S. Greenhouse Gas Inventory Report: 1990-2014." (2016). 


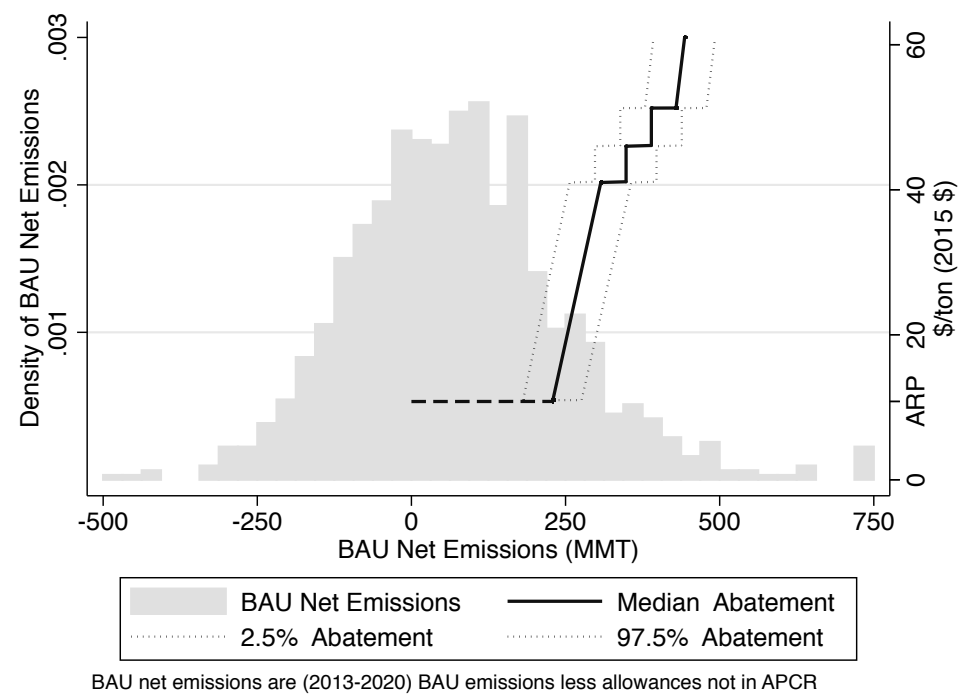

Figure A.3: Net Emissions and Abatement Supply with No Complementary Policies (2013-2020)

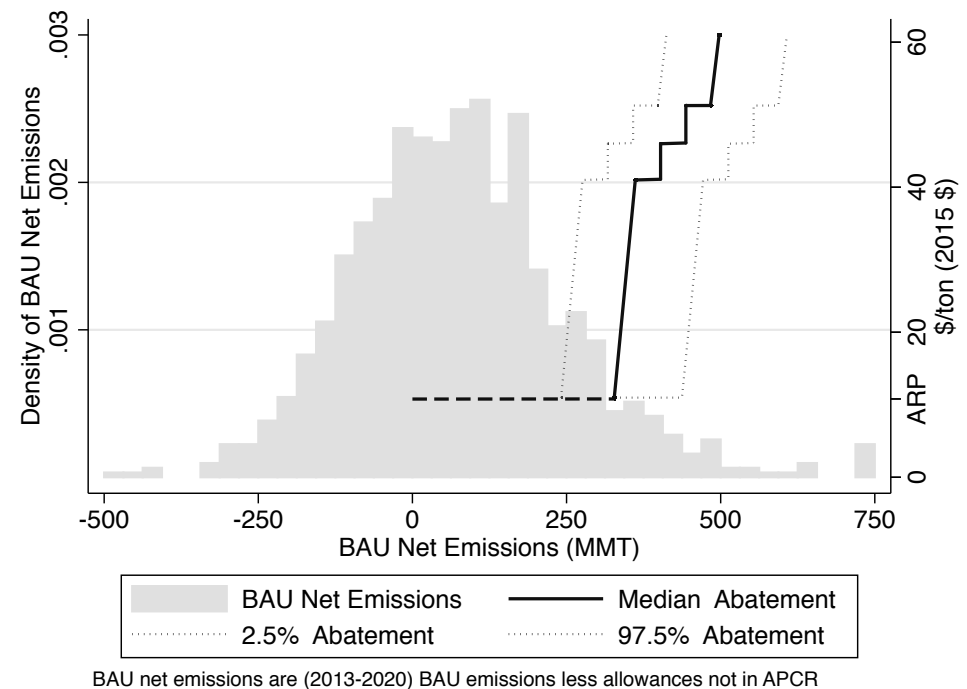

Figure A.4: Net Emissions and Abatement Supply with Complementary Policies (2013-2020)//(Reproduces Figure 4 from text) 

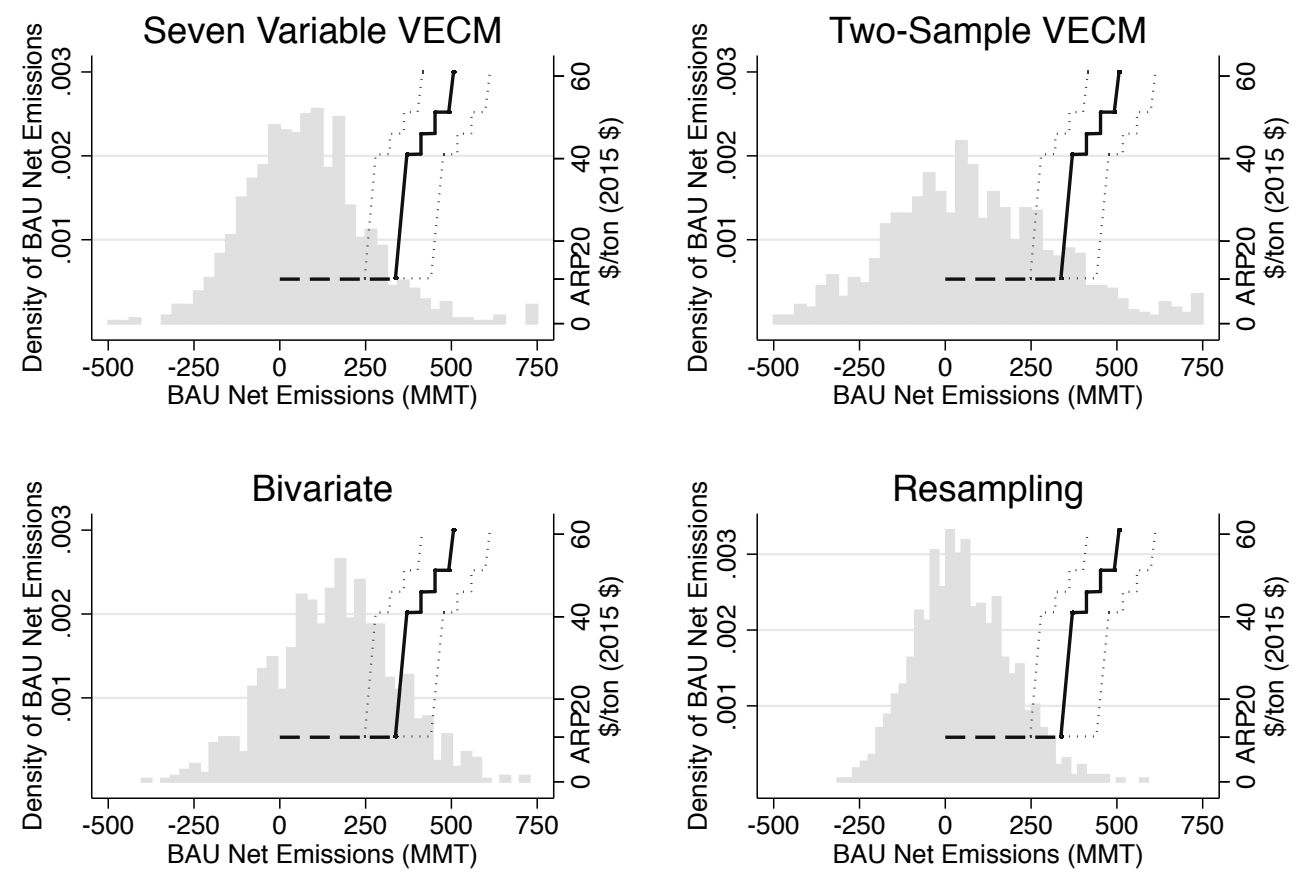

Abatement supply is based upon our base results in all cases

Figure A.5: Net Emissions and Abatement Supply Under Alternative Approaches to BAU Estimation 